7

8 1

\title{
Legionella pneumophila regulates host cell motility by targeting Phldb2 with a
}

\section{4-3-3ろ-dependent protease effector}

\section{Lei Song ${ }^{1 * \dagger}$, Jingjing Luo ${ }^{1^{*}}$, Dan Huang ${ }^{1}$, Yunhao Tan ${ }^{2}$, Yao Liu ${ }^{2}$, Kaiwen $\mathrm{Yu}^{3}$, Yong} Zhang $^{1}$, Xiaoyun $\mathrm{Liu}^{3}$, Dan $\mathrm{Li}^{1 \dagger}$ and Zhao-Qing Luo ${ }^{2 \dagger}$

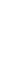
7

${ }^{1}$ Department of Respiratory Medicine, Center for Pathogen Biology and Infectious 9 Diseases, Key Laboratory of Organ Regeneration and Transplantation of the Ministry of 0 Education, State Key Laboratory for Zoonotic Diseases, The First Hospital of Jilin 1 University, Changchun 130021, China

$2{ }^{2}$ Department of Biological Sciences, Purdue University, West Lafayette, IN 47907 USA $3{ }^{3}$ Department of Microbiology, School of Basic Medical Sciences, Peking University 4 Health Science Center, Beijing, 100191 China

$7 \quad$ *Equal contribution authors

9 †Correspondence: Isong@jlu.edu.cn, li_dan@jlu.edu.cn and luoz@purdue.edu 20 
24 The cytoskeleton network of eukaryotic cells is essential for diverse cellular processes, 25 including vesicle trafficking, cell motility and immunity, thus is a common target for bacterial virulence factors. A number of effectors from the bacterial pathogen Legionella pneumophila have been shown to modulate the function of host actin cytoskeleton to construct the Legionella-containing vacuole (LCV) permissive for its intracellular replication. In this study, we found that the Dot/lcm effector Lem8 (Lpg1290) is a protease whose activity is catalyzed by a Cys-His-Asp motif known to be associated with diverse biochemical activities. Intriguingly, we found that Lem8 interacts with the host regulatory protein $14-3-3 \zeta$, which activates its protease activity. Furthermore, Lem8 undergoes self-cleavage in a process that requires $14-3-3 \zeta$. We identified the Pleckstrin

34 homology-like domain-containing protein Phldb2 involved in cytoskeleton organization as a target of Lem8 and demonstrated that Lem8 plays a role in the inhibition of host cell migration by attacking Phldb2.

Key words: bacterial virulence, cell migration, cytoskeleton, cysteine protease, self-cleavage 


\section{Introduction}

Legionella pneumophila is a Gram-negative intracellular bacterial pathogen ubiquitously found in freshwater habitats, where it replicates in a wide range of amoebae (Richards et al., 2013). It is believed that these natural hosts serve as the main replication niches for $L$. pneumophila in the environment and provide the primary evolutionary pressure for the acquisition and maintenance of virulence factors necessary for its intracellular lifecycle. Infection of humans by L. pneumophila occurs when susceptible individuals inhale aerosols generated from contaminated water, which introduces the bacterium to the lungs where it is phagocytosed by alveolar macrophages. Instead of being digested and cleared, internalized bacteria replicate within a membrane-bound compartment termed Legionella-containing vacuole (LCV), leading to the development of Legionnaires' disease, a form of severe pneumonia (Cunha et al., 2016).

One feature associated with the LCV is its ability to evade fusion with the lysosomal network in the early phase $(<8 \mathrm{~h}$ post-infection in mouse bone marrow-derived macrophages(BMDMs)) of its development and the quick acquisition of proteins originating from the endoplasmic reticulum (ER) (Kagan and Roy, 2002; Sturgill-Koszycki and Swanson, 2000; Swanson and Isberg, 1995). Biogenesis of the LCV requires the Dot/Icm type IV secretion system that injects more than 300 effector proteins into host cells (Qiu and Luo, 2017). These effectors function to modulate a wide cohort of host processes, including vesicle trafficking (Tan et al., 2011), protein synthesis (Shen et al., 2009), lipid metabolism (Gaspar and Machner, 2014), and autophagy (Choy et al., 2012) by diverse biochemical mechanisms. Coordinated activity of these effectors leads to the formation of the LCV which largely resembles the ER in its morphology and protein composition (Qiu and Luo, 2017).

The cytoskeleton of eukaryotic cells is composed of microfilaments derived from actin polymers, intermediate filaments and microtubules, which play distinct roles in maintaining cell shape, migration, endocytosis, intracellular transport and the association of cells with the extracellular matrix and cell-cell interactions (Jones et al., 2019). Due to its essential role in these cellular processes, components of the 
cytoskeleton, particularly the actin cytoskeleton is a common target for infectious agents. For example, Salmonella enterica Typhimurium utilizes a set of type III effectors, including SipC, SopE and SptP to reversibly regulate the rearrangement of the host actin cytoskeleton to facilitate its entry into non-phagocytic cells (Kubori and Galan, 2003). Other bacterial pathogens such as Chlamydia, Orientia tsutsugamushi, and Listeria also exploit the actin cytoskeleton and microtubule networks to promote their movement in the cytoplasm of host cells and cell to cell spread (Cheng et al., 2018; Grieshaber et al., 2003; Kim et al., 2001).

Growing evidence indicates that manipulation of the actin cytoskeleton dynamics plays an important role in the intracellular lifecycle of $L$. pneumophila. It has been documented that chemical interference of the actin cytoskeleton structure impedes bacterial entry and replication (Charpentier et al., 2009). A number of Dot/lcm effectors have been shown to impose complex modulation of the host actin cytoskeleton. Among these, VipA promotes actin polymerization by functioning as a nucleator (Franco et al., 2012). LegK2 appears to inhibit actin nucleation by phosphorylating the Arp2/3 complex (Michard et al., 2015). The protein phosphatase WipA participate in this regulation by dephosphorylating several proteins involved in actin polymerization, including N-WASP, NCK1, ARP3, and ACK1, leading to dysregulation of actin polymerization (He et al., 2019). RavK is a metalloprotease that cleaves actin in host cells, abolishing its ability to form polymers (Liu et al., 2017). Ceg14 also appears to inhibit actin polymerization by a yet unrecognized mechanism (Guo et al., 2014). Interestingly, LegG1 has been demonstrated to promote microtubule polymerization and host cell migration by functioning as a guanine nucleotide exchange factor (GEF) for the Ran GTPase (Rothmeier et al., 2013; Simon et al., 2014). Counterintuitive to the role of LegG1, cells infected by L. pneumophila display defects in migration in a way that requires a functional Dot/lcm system (Simon et al., 2014), suggesting the existence of effectors that function to block cell migration.

Herein, we demonstrate that the L. pneumophila effector Lem8 (Lpg1290) (Burstein et al., 2009) is a cysteine protease that functions to inhibit host cell migration by targeting the microtubule-associated protein Phldb2 via a mechanism that requires the 
regulatory protein $14-3-3 \zeta$.

\section{Results}

\section{Lem8 is a Legionella effector with putative cysteine protease activities}

One major challenge in the study of bacterial effectors is their unique primary sequences that share little similarity with proteins of known function. Bioinformatics analysis has been proven useful in the identification of putative cryptic functional motifs embedded in their structures. We used PSI-BLAST to analyze a library of the $L$. pneumophila Dot/lcm effectors (Zhu et al., 2011) and found that Lem8 harbors a putative Cys $_{280}-\mathrm{His}_{391}-\mathrm{Asp}_{412}$ catalytic triad present in a variety of cysteine proteases (Fig. 1A). Further analysis by HHpred (Soding et al., 2005) revealed that Lem8 has high probability to have structural similarity with HopN1 and AvrPphB from Pseudomonas syringae (Rodriguez-Herva et al., 2012; Shao et al., 2002), as well as YopT from Yersinia enterocolitica (Shao et al., 2002) and PfhB1 from Pasteurella multocida (Shao et al., 2002) (Fig. S1).

Lem8 is a protein of 528 residues coded for by the gene Ipg1290 in L. pneumophila strain Philadelphia 1, it was first identified as a substrate of the Dot/lcm transporter by a machine learning approach (Burstein et al., 2009). The translocation of Lem8 by the Dot/lcm system into host cells during L. pneumophila infection was later validated by two independent reporter systems (Huang et al., 2011; Zhu et al., 2011). Consistent with these results, we observed Dot/lcm-dependent translocation of Lem8 into host cells using the $\beta$-lactamase- and CCF2-based reporter assay. Approximately $60 \%$ of the cells infected with a Dot/lcm competent strain expressing the $\beta$-lactamase-fusion emited blue fluorescence signals. No translocation was detected when the same fusion was expressed in the $\operatorname{dot} A^{-}$mutant defective in the Dot/lcm system (Berger and Isberg, 1993) (Fig. 1B).

The expression of many Dot/lcm substrates peaks in the post-exponential phase, probably due to the demand for high quantity of effectors to thwart host defense in the initial phase of LCV construction (Luo and Isberg, 2004; Segal, 2013). Thus, we 
evaluated the expression pattern of lem8 throughout the entire growth cycle of $L$. pneumophila in broth. Intriguingly, unlike most of effectors, the expression of lem8 is detected at high levels in the lag phase of its growth cycle in bacteriological medium. A decrease in protein abundance is detected $9 \mathrm{~h}$ after the subcultures have started and is maintained constant throughout the remaining $15 \mathrm{~h}$ experimental duration (Fig. 1C). These results suggest that Lem8 may play a role in the entire intracellular lifecycle of $L$. pneumophila.

Next, we attempted to determine whether the putative cysteine protease motif is important for the effects of Lem8 on eukaryotic cells. We first tested whether Lem8 is toxic to yeast and if so, whether the $\mathrm{Cys}_{280}-\mathrm{His}_{391}-\mathrm{Asp}_{412}$ motif is required for such toxicity. Expression of Lem8 from the galactose-inducibe promoter caused cell growth arrest (Fig. 1D). Mutations in $\mathrm{Cys}_{280}, \mathrm{His}_{391}$ or $\mathrm{Asp}_{412}$ did not affect the stability of the protein in yeast, but abolished such toxicity (Fig. 1D). Thus, the putative cysteine protease activity conferred by the predicted $\mathrm{Cys}_{280}-\mathrm{Hi} \mathrm{s}_{391}-\mathrm{Asp}_{412}$ catalytic triad very likely is important for the effects of Lem8 on eukaryotic cells.

Genomic analysis reveals that Lem8 orthologs are present in several different (Qiu and Luo, 2017). 2020), LPE509 (Ma et al., 2013), Paris (Cazalet et al., 2004), HL06041035 (Gomez-Valero et al., 2011) and strain ATCC 43290 (serogroup 12) (Gomez-Valero et al., 2011). In addition, a lem8 homolog is also present in L. waltersii, one of the 40 Legionella species whose genomes had been fully sequenced (Burstein et al., 2016). Such a low prevalence suggests that Lem8 plays a role in the survival of the bacteria in specific inhabits, or its role in other Legionella species is substituted by genes of little sequence similarity that may have arisen by convergent evolution. We probed the role of lem8 in L. pneumophila virulence by examining intracellular replication of the $\Delta / e m 8$ mutant in the protozoan host Dictyostelium discoideum and in BMDMs. In both host cells, intracellular growth of the $\Delta / e m 8$ mutant was indistinguishable to that of the wild-type strain (Fig. S2), which is akin to most mutants lacking one single Dot/lcm substrate gene 


\section{Lem8 directly interacts with the regulatory protein $14-3-3 \zeta$}

To identify the host target of Lem8, we performed a yeast two-hybrid screening against a human cDNA Library (BD Biosciences) using Lem8 ${ }_{\mathrm{C} 280 \mathrm{~s}}$ fused to the DNA binding domain of the transcriptional factor GAL4 as bait. Plasmid DNA of the library was introduced into the yeast strain PJ69-4A (James et al., 1996) expressing the bait fusion and colonies that appeared on selective medium were isolated and the inserts of the rescued plasmids capable of conferring the interactions were sequenced. We found that 50 out of the 93 independent clones analyzed harbored portions of the gene coding for 14-3-3ろ, a member of a chaperone family important for the activity of a wide variety of proteins in eukaryotic cells (Pennington et al., 2018). Robust interactions occurred in the yeast two-hybrid system when full-length $14-3-3 \zeta$ was fused to the AD domain of Gal4 (Fig. 2A). The remaining clones were not pursued further as the interactions cannot be confirmed by immunoprecipitation or the proteins are common false positive hits in yeast two-hybrid screenings or/and appeared not relevant to the life cycle of $L$. pneumophila (Table S1).

We further explored the interactions between 14-3-3 $\zeta$ and Lem8 by

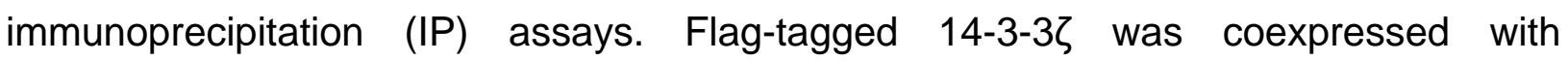
GFP-tagged Lem8 or GFP in HEK293 cells. IP using the Flag antibody specifically precipitated GFP-Lem8, whereas GFP was not detectable in similar experiments. Reciprocally, IP with GFP antibodies specifically pulled down Flag-14-3-3ろ (Fig. 2B). These results suggest that Lem8 forms a complex with 14-3-3 $\zeta$ in mammalian cells.

To determine whether Lem8 directly binds to $14-3-3 \zeta$, we purified recombinant proteins and used GST pulldown assays to analyze their interactions. We found that mixing $\mathrm{His}_{6}$-Lem8 and GST-14-3-3弓 in reactions led to the formation of stable protein complexes that can be retained by GST beads (Fig. 2C).

Members of the 14-3-3 family commonly recognize phospho-serine and/or phospho-threonine sites of client proteins for binding (Muslin et al., 1996). Yet, we did not detect phosphorylation on Lem8 purified from mammalian cells or Escherichia coli using a pan phospho-serine/threonine antibody. As a control, this antibody detected phosphorylation on CTNNB1, an established phosphorylated target of 14-3-3ろ (Tian et 
al., 2004).

To determine the region in Lem8 involved in binding 14-3-3 3 , we constructed a series of Lem8 deletion mutants and examined their interactions with $14-3-3 \zeta$ by immunoprecipitation. Whereas removing as few as 25 residues from the amino terminal end of Lem8 abolished its ability to bind $14-3-3 \zeta$, a Lem8 mutant lacking the last 50 residues can still robustly interact with 14-3-3ろ, and deleting an additional 50 residues from this end abolished the binding (Fig. 2D). Thus, either $14-3-3 \zeta$ recognizes a large region of Lem8 or deletion from either end of this protein caused significant disruptions in its structure and abolished its ability to interact with 14-3-3ろ.

\section{Lem8 undergoes 14-3-3ろ-dependent auto-cleavage}

Since Lem8 harbors the predicted $\mathrm{Cys}_{280}-\mathrm{His}_{391}-\mathrm{Asp}_{412}$ catalytic triad associated with proteases from diverse bacterial pathogens, we next investigated whether it cleaves 14-3-3ろ. Incubation of recombinant $\mathrm{His}_{6}$-Lem8 with $\mathrm{His}_{6}-14-3-3 \zeta$ at room temperature for

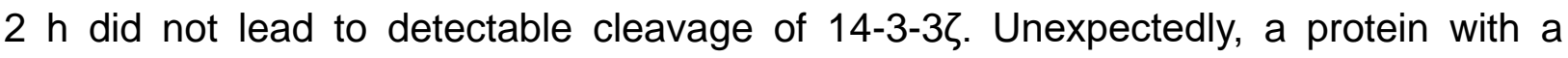
molecular weight slightly smaller than that of Lem8 was detected in this reaction (Fig. 3A). The production of this smaller protein did not occur in reactions that contained the Lem8 ${ }_{\mathrm{C} 280 \mathrm{~S}}$ mutatant or when the cysteine protease-specific inhibitor E64 was included in the reactions (Fig. 3A), suggesting that this band represents a fragment of Lem8 produced by self-cleavage. Intriguingly, the self-cleavage did not occur in samples containing only Lem8, suggesting that the self-cleavage activity of Lem8 requires 14-3-3ろ as a co-factor.

Dictyostelium discoideum, the protozoan host of $L$. pneumophila codes for one 14-3-3 protein with $66 \%$ identity and $78 \%$ similarity to that of human $14-3-3 \zeta$ (Eichinger et al., 2005), we investigated whether the D. discoideum 14-3-3 (14-3-3Dd) can activate

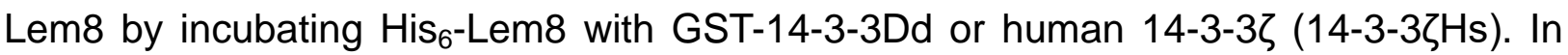
each case, we observed the production of a protein with a size clearly smaller than Lem8 as early as $2 \mathrm{~h}$ after the reaction has started (Fig. 3B). Thus, Lem8 can be activated by 14-3-3 from both humans and a protist.

To determine the self-cleavage site of Lem8, we incubated His Hem8 $_{6}$ with 
$\mathrm{His}_{6}-14-3-3 \zeta$ at room temperature for $16 \mathrm{~h}$. Proteins resolved by SDS-PAGE were stained with Coomassie brilliant blue and bands corresponding to full-length and cleaved Lem8 were excised, digested with trypsin and sequenced by mass spectrometry, respectively (Fig. 3C). To determine the potential self-cleavage site, we compared the abundance of identified tryptic peptides from full-length and cleaved Lem8 and found that the abundance of $-\mathrm{A}_{468} \mathrm{PQPTPQR} \mathrm{R}_{45^{-}}$was similar between two sets of samples, whereas peptide $-A_{478} Q_{S L S A E T E R}{ }_{487}$ - was present only in full-length samples but not in the cleaved ones (Fig. S4A), suggesting that the cleavage site was between R475 and R487. Further analysis of the tryptic fragments identified a semi-tryptic fragment ${ }^{-}{ }_{464}$ CEKAPQPTPQRQ ${ }_{476}$ - present in the cleaved protein but not in the full-length protein, indicating that the cleavage occurs between Gln476 and Arg477 (Fig. 3C).

We further examined the self-cleavage of Lem8 by fusing GFP to the carboxyl end of Lem8, Lem8 $8_{C 280 S}$ and Lem8 $8_{\triangle C 52}$, respectively. These fusion proteins were expressed in HEK293T cells and the cleavage was probed by immunoblotting with GFP-specific antibodies. We found that a fraction of Lem8-GFP and Lem8 $\triangle_{\triangle \mathrm{C} 52}$-GFP has lost the GFP portion of the fusions, an event that did not occur in Lem8 ${ }_{\mathrm{C} 280 \mathrm{~S}}$-GFP (Fig. S4B). To determine whether Lem8 undergoes auto-cleavage via the recognition of the protein sequence around $G \mathrm{In}_{476}$, we introduced mutations to replace residues $\mathrm{PrO}_{473}, \mathrm{G} / \mathrm{n}_{474}$,

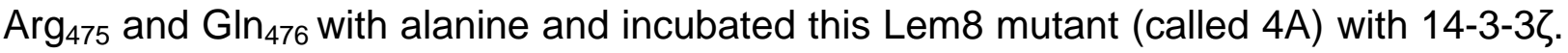
Unexpectedly, although at a lower rate, self-cleavage still occurred in this mutant (Fig. 3D). Thus, although the amino acids adjacent to Gln476 play a role in its self-cleavage, other factors such as the overall structure of Lem8 may contribute to the recognition of the cleavage site. We next analyzed the self-cleaved products of the $4 \mathrm{~A}$ mutant and found that the cleavage site in this protein lies between Lys467 and Ala468, which is in close proximity to the one found in the wild-type protein (Fig. S4C). Thus, the self-cleavage of Lem8 may occur at at least two sites that locate at approximately 50 residues from its carboxyl end.

\section{Lem8 targets Phldb2 for cleavage}

It has been reported that some bacterial cysteine proteases cleave both themselves and their substrates in host cells by recognizing sites with similar sequences. For 
instance, AvrpphB and Avrrpt2, two type III effectors from P. syringae cleave themselves as well as their host targets PBS1 and RIN4, respectively (Chisholm et al., 2005; Shao et al., 2003). Importantly, in each case, the sequences of the recognition sites for both self-cleavage and cellular target cleavage are very similar. In fact, this feature has been exploited to predict the potential host substrates of these effectors by bioinformatic analyses. Therefore, we performed BLAST searches and obtained 10 candidate proteins that contain sequence elements resembling the self-cleavage site of Lem8, including Phldb2, Rasgrp2, Pak6, Exoc8, Ankrd13B, Chkb, Ppp6R1, Kiaa1033, Gnal and Gpr61. The predicted recognition sites in these proteins locate in the middle or at sites close to either their amino or carboxyl ends (Fig. 4A). Further experiments revealed that one of the candidates, the Pleckstrin homology-like domain family $B$ member 2 (Phldb2) can be cleaved by Lem8 in a process that requires an intact Cys $_{280}-\mathrm{His}_{391}-\mathrm{Asp}_{412}$ catalytic triad. In contrast, no detectable cleavage occurred in reactions containing recombinant proteins of other candidates purified from mammalian cells (Fig. S5A). We cannot detect the expression of Flag- or HA-GPR61 using multiple constructs and this protein was not analyzed further. The predicted Lem8 recognition site locates between the $1106^{\text {th }}$ residue and the $1119^{\text {th }}$ residue in this protein of 1253 amino acids (Fig. 4A). In HEK293T cells, expression of Lem8 led to a considerable reduction of endogenous Phldb2 (Fig. 4B). To confirm this finding, we added an HA and a Flag tag to the amino and carboxyl end of Phldb2 respectively, and co-expressed the double tagged protein in HEK293T cells with Lem8 or each of the mutants with mutations in one of the three sites (C280S, H391A and D412A) predicted to be critical for catalysis. Detection of tagged Phldb2 by immunoblotting with the Flag-specific antibody indicated that the protein levels in cells expressing Lem8 were reduced comparing to samples in which the catalytically inactive mutants were expressed. Athough to a lesser extent, reduction in Phldb2 was also observed in experiments in which the tagged protein was detected with the HA antibody (Fig. 4C).

Phldb2 is plasma membrane associated protein that contains a phosphatidylinositol-3,4,5-triphosphate (PIP3)-binding domain located at its carboxyl terminus (Paranavitane et al., 2003), we next examined how Lem8-mediated cleavage 
impacts its cellular localization. In HEK293T cells, when GFP-Phldb2 was ectopically expressed, the GFP signals mainly were associated with the plasma membrane, and this pattern of distribution remains unchanged in cells co-expressing enzymatically inactive Lem8 mutants (Fig. 4D). In constrast, in cells co-expressing wild-type Lem8, the GFP signals redistributed to occupy the entire cytoplasm, including the nuclei of transfected cells, a pattern similar to that of GFP itself (Fig. 4D). These observations suggest that the GFP tag had been cleaved from the GFP-Phldb2 fusion to assume its typical localization in these cells. We also analyzed how Lem8 impacts the subcellular localization of endogenous Phldb2. In cells expressing mCherry-Lem8 ${ }_{\mathrm{c} 280 \mathrm{~s}}$, Phldb2 is mainly associated with the plasma membrane. In contrast, in cells expressing mCherry-Lem8, the association of Phldb2 with the plasma membrane almost became undetectable (Fig. S5B).

We next examined whether the cleavage of Phldb2 by Lem8 occurs in a cell-free reaction. HA-Phldb2-Flag expressed in HEK293T cells isolated by immunoprecipitation was incubated with Lem8 or its inactive mutants with or without 14-3-3ろ. Cleavage of Phldb2 occurred only in reactions containing wild-type Lem8 and 14-3-3ろ (Fig. 4E). Taken together, these results establish Phldb2 as a target of Lem8.

Our results using the double tagged Phldb2 suggest that Lem8 likely cleaves Phldb2 not only at the predicted site located in the carboxyl end of the protein, but also targets its amino terminal portion (Fig. 4C-E). To test this hypothesis, we constructed two Phldb2 mutants by replacing residues $\operatorname{Arg}_{1111}$ and $\mathrm{Gln}_{1112}\left(\mathrm{Phldb} 2_{\mathrm{AA1}}\right)$ or $\mathrm{Gl}_{1112}$ and $\operatorname{Arg}_{1113}\left(\mathrm{Phldb}_{\mathrm{AA} 2}\right)$ within the predicted recognition sequence with alanine. Each of these mutants was co-expressed with Lem8 in HEK293T cells by transfection. Comparing to samples expressing enzymatically inactive Lem8, the amounts of protein detected by the amino terminal Flag epitope and the carboxyl end HA tag both decreased in cells co-expressing wild-type Lem8 (Fig. S5B). We validated this conclusion by making constructs in which GFP was fused to the amino terminal end of Phldb2 and three of its truncation mutants, Phldb2 $2_{\triangle N 50}$, Phldb2 $\triangle$ N100 and Phldb2 ${ }_{\triangle \mathrm{N} 200}$, respectively. Each of these fusion proteins was co-expressed with Lem8 or Lem8 ${ }_{\mathrm{c} 280 \mathrm{~s}}$ in HEK293T cells and the protein level of these fusions was probed by immunoblotting with 
311 GFP-specific antibodies. In each case, a fraction of the protein has lost the GFP portion

312 of the fusions when co-expressed with Lem8 but not with Lem8 ${ }_{\mathrm{c} 280 \mathrm{~s}}$ (Fig. S5C).

313 Intriguingly, the cleavage also occurred in fusion proteins in which the GFP is fused to

314 the carboxyl terminus of $\mathrm{Phldb}_{\Delta \mathrm{C} 100}$ or Phldb2 ${ }_{\Delta \mathrm{C} 153}$ (Fig. S5D, right panel). These

315 results are consistent with the notion that Lem8 targets Phldb2 at multiple sites.

316 We also attempted to detect Lem8-mediated cleavage of endogenous Phldb2 in cells infected with L. pneumophila. Although Lem8 translocated into infected cells by a Dot/lcm-competent strain expressing Lem8 from a multicopy plasmid is readily detetable, we were unable to detect Phldb2 cleavage in these samples (Fig. S5E). The most likely reason for the inability to detect Lem8 activity against Phldb2 in infected cells is the low abundance or instability of the cleaved protein or a combination of both.

A coiled coil motif in the amino terminal region of Lem8 is important for its interactions with 14-3-3ろ

Using the online MARCOIL sequence analysis software (Gabler et al., 2020), we identified a putative coiled coil motif located in the amino region of Lem8. Coiled coil is a common structural element in proteins, particularly those of eukaryotic origin; it is formed by 2-7 supercoiled alpha-helices (Liu et al., 2006), and often is involved in protein-protein interactions, thus playing important roles in the formation of protein complexes (Burkhard et al., 2001). To determine the role of this region in the activity of Lem8, we introduced mutations to replace $\mathrm{Leu}_{58}$ and $\mathrm{Glu}_{59}$, the two sites predicted to be essential for the coiled coil structure in Lem8, with glycine (called Lem8 ${ }_{G G}$ ) (Fig. 5A). When tested in yeast, these mutations have completely abolished the toxicity of Lem8 without affecting its expression or stability (Fig. 5B). These mutations may affect the cysteine protease acitivity of Lem8, its interaction with the regulatory protein $14-3-3 \zeta$ or its ability to recognize substrates.

We examined the ability of Lem8 ${ }_{G G}$ to cleave Phldb2 by coexpressing them in HEK293T cells. Whereas wild-type Lem8 consistently cleaves this substrate, Lem8 ${ }_{G G}$ has lost such activity despite a similar expression level (Fig. 5C). To test the

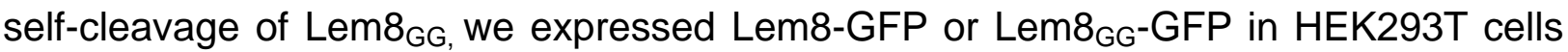


and probed the fusion proteins by immunoblotting with GFP-specific antibodies.

342 Comparing to Lem8-GFP, the levels of full-length proteins of Lem8-GFP and

343 Lem8 $_{\mathrm{C} 280 \mathrm{~S}}$-GFP were similar, both were slightly higher than that of Lem8 $8_{\mathrm{GG}}$-GFP and 344 loss of the GFP portion of the protein occurred in the wild-type fusion but not in either of 345 the two mutants (Fig. 5D), indicating that the putative coiled coil domain is important for the self-cleavage activity of Lem8. Finally, we examined the impact of these mutations on the interaction between Lem8 and 14-3-3ろ. Albeit Lem8 $8_{\mathrm{GG}}$ expressed similarly to the wild-type, it has largely lost the ability to bind $14-3-3 \zeta$ in immunoprecipitation assays (Fig. 5E). Together with the observation that Lem8 mutants lacking as few as 25 residues from its amino terminal end are unable to bind $14-3-3 \zeta$, these results suggest that the regulatory protein most likely binds Lem8 by recognizing the coiled coil motif located in its amino end region.

\section{Auto-cleaved Lem8 maintains the cysteine protease activity}

It has been well-established that some proteins, particularly enzymes are made as precursors or zymogens that need either auto-processing or cleavage by other enzymes to exhibit their biological functions. One such example is caspases involved in cell death regulation and other important cellular functions. These enzymes are synthesized as zymogens before being activated by proteolytic cleavage in response to stimulation (Shalini et al., 2015). In some cases, auto-processing leads to changes or even loss of their enzymatic activity (Kapust et al., 2001; Zhang et al., 2018). To investigate whether Lem8 that has undergone self-cleavage still possesses the cysteine protease activity, we tested the cleavage of Phldb2 by Lem8 $8_{\Delta c 52}$, its self-processed form. Similar to full-length Lem8, Lem8 ${ }_{\Delta \mathrm{C} 52}$ was able to reduce the protein levels of Phldb2. In contrast, other truncation mutants, including $\operatorname{Lem}_{\Delta \mathrm{N} 25}$ and $\operatorname{Lem}_{\Delta \mathrm{N} 50}$ have lost the capacity to cleave Phldb2, while Lem8 ${ }_{\Delta \mathrm{C} 100}$ is poorly expressed in cells (Fig. 6A). In addition, Lem8 $8_{\Delta C 52}$, but not Lem $_{\Delta N 25}$ or Lem8 $8_{\Delta C 100}$, cleaved the GFP tag from from the GFP-Phldb2 fusion and released the GFP signals from the plasma membrane (Fig. 6B). Intriguigingly, although their ability to cleave Phldb2 appears similar, under our experimental conditions, the protein level of Lem8 ${ }_{\Delta C 52}$ is considerably lower than that of 
Lem8 (Fig. 6A), suggesting that the self-processed form has higher activity.

We next examined whether the protease activity of Lem8 ${ }_{\Delta C 52}$ still requires $14-3-3 \zeta$ binding. Results from immunoprecipitation and pulldown assays with purified protiens

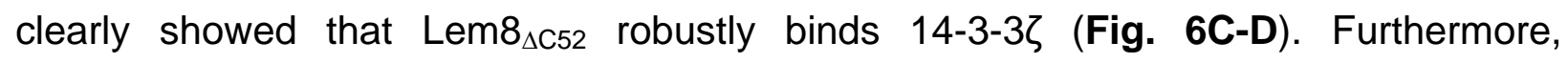
incubation of Lem8 ${ }_{\Delta \mathrm{C} 52}$ with Phldb2 isolated from cells did not lead to its cleavage, but the inclusion of $14-3-3 \zeta$ in this reaction led to cleavage (Fig. 6E), indicating that Lem8 ${ }_{\Delta C 52}$ still requires $14-3-3 \zeta$ for its protease activity.

\section{Lem8 inhibits mammalian cell migration}

Phldb2 is a PIP3 binding protein involved in microtubule stabilization (Lansbergen et al., 2006; Paranavitane et al., 2003), thus playing a pivotal role in cell motility. Depletion of Phldb2 significantly reduces the migration of MDA-231 cells in the haptotactic migration assay (Astro et al., 2014). As Lem8 cleaves Phldb2, we hypothesized that Lem8 may affect cell migration. To test this, we first established HEK293T-derived cell lines that stably express GFP, GFP-Lem8 or GFP-Lem8c280s. Immunoblotting confirmed that Lem8 and Lem8 ${ }_{\mathrm{C} 280 S}$ robustly expressed in the respective cell lines. Furthermore, in the cell line expressing Lem8, the level of Phldb2 was drastically reduced comparing to that in the line expressing GFP or Lem8c280s (Fig. 7A). We then used the wound-healing scratch assay (De leso and Pei, 2018) to examine the impact of ectopic Lem8 expression on cell motility. Confluent monolayers of each cell lines were scratched using a pipette tip and the migration of cells into the gap was monitored over a period of $24 \mathrm{~h}$. Results from this experiment showed that the percentage of wound closure at $24 \mathrm{~h}$ after wounding was around $50 \%$ in samples using

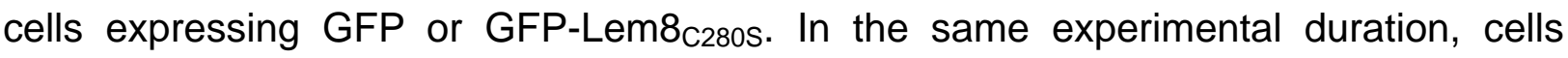
expressing GFP-Lem8 only filled the gap by $26 \%$, which was significantly slower than that of the controls (Fig. 7B). Thus, ectopic expression of Lem8 inhibits mammalian cell migration.

An earlier study has shown that in the under-agarose migration assay, $L$. pneumophila inhibits the chemotaxis of mouse macrophages towards cytokines CCL5 and TNF-a in a Dot/lcm-dependent manner (Simon et al., 2014). Yet, the Dot/lcm 
substrates responsible for this inhibition remain elusive. We further studied whether Lem8 contributes to the inhibition of infected cell migration. To test this, we performed the scratch assay with 293T cells and Raw264.7 cells infected with relevant $L$. pneumophila strains (Fig. 7C-D). The percentage of wound closure by cells infected with wild-type L. pneumophila or $\Delta / e m 8$ (pLem8) was significantly lower than that with cells infected with the $\Delta l e m 8$ mutant. Consistent with its lack of the protease activity, Lem8 $8_{\mathrm{C} 280 \mathrm{~S}}$ and Lem8 $\mathrm{GG}_{\mathrm{G}}$ was unable to complement the defects displayed by the $\Delta / e m 8$ mutant (Fig. 7C-D). Thus, the inhibition of cell migration by $L$. pneumophila during infection is caused at least in part by the activity of Lem8.

To confirm the notion that Lem8 inhibits cell migration by attacking Phldb2, we performed the cell scratch assays using Lem8 expressing cells that had been transfected to ectopically express Phldb2. The level of Phldb2 in these cells considerably increased comparing to those transfected with a vector (Fig. S6A). Importantly, the closure of the gap by cells overexpressing Phldb2 occurred significantly faster than those transfected with the vector (Fig. S6B), validating our conclusion that Lem8 inhibits cell migration by attacking Phldb2.

\section{Discussion}

Intracellular bacteria manipulate cellular processes to create a niche that supports their survival and replication in host cells by virulence factors that target proteins important for the regulation of these processes. These virulence factors often attack host regulatory proteins by diverse posttranslational modifications (PTMs) such as phosphorylation (Krachler et al., 2011), ubiquitination (Zhou and Zhu, 2015), AMPylation (Yarbrough et al., 2009), acetylation (Mukherjee et al., 2006) and ADP-ribosylation (Cohen and Chang, 2018). Proteolytic processing is a type of PTM that can lead to the activation, inactivation or destruction of target proteins, causing alterations in cellular structure or signaling that benefit the pathogen. For instance, the type III effector EspL from enteropathogenic Escherichia coli functions as a cysteine protease that antagonizes host inflammatory response by degrading several proteins involved in necroptotic signalling (Pearson et al., 2017). Our results herein establish Lem8 as a 
cysteine protease that directly targets the microtubule associated protein Phldb2, therefore contributing to the inhibition of host cell migration by L. pneumophila. Lem8 joins a growing list of Legionella effectors with protease activity, including the serine protease Lpg1137 that inhibits autophagy by cleaving syntaxin 17 (Arasaki et al., 2017) and the metalloprotease RavK that attacks actin to disrupt the actin cytoskeleton of host cells (Liu et al., 2017).

One interesting feature associated with Lem8 is the requirement of $14-3-3 \zeta$ for its activity. In line with the notion that amoebae are the primary host of L. pneumophila, the sole 14-3-3 protein from $D$. discoideum similarly activates Lem8. Due to extremely low bacterial uptake rates by $D$. discoideum, we were unable to examine the impact of Lem8 on the motility of this host. Nevertheless, despite Lem8 is not required for intracellular bacterial replication, it plays a role in $L$. pneumophila virulence by inhibiting host cell motility, this finding thus provides a molecular explanation for this phenotype observed earlier (Simon et al., 2014). It is worth noting that a close homolog of Phldb2 is not present in amoebae species such as $D$. discoideum. The fact that lem 8 is only present in a few isolates of the many sequenced $L$. pneumophila strains implies that these bacteria may have coevolved with higher eukaryotes. Several L. pneumophila Dot/lcm effectors that attacks host signaling mechanisms not known to exist in amoebae have been reported. For example, the activation of the NFКB pathway by LegK1 (Ge et al., 2009) and the specific attack of linear polyubiquitin chains by RavD (Wan et al., 2019). These two signaing mechanisms are not present in lower eukaryotes such as amoebae (Iwai, 2021; Li and Verma, 2002). It is tempting to speculate that Lem8 has been acquired by strains of L. pneumophila that have coevolved with hosts that use Phldb2 or its close homologs to control cell motility.

In mammals, members of the 14-3-3 family, including 14-3-3 $\zeta$ often bind their client proteins by recognizing phosphorylated pockets with relatively conserved sequences such as RSX[pS/pT]XP (mode I) and RXXX[pS/pT]XP (mode II) (pS, phospho-serine, pT, phospho-threonine, $X$, any residue) (Morrison, 2009). Intriguingly, neither of these two motifs is present in Lem8. Consistently, recombinant Lem8 from mammalian cells or $E$. coli was not detectably phosphorylated (Fig. S3). The binding of 14-3-3 proteins to 
unmodified clients is not unprecedented. All isoforms of 14-3-3 bind non-phosphorylated

462 ExoS of $P$. aeruginosa by recongnizing the DALDL element (Henriksson et al., 2002), which bears sequence similarity to the unphosphorylated target WLDLE, an artificial R18 peptide inhibitor derived from a phage display library (Petosa et al., 1998).

Elements with a sequence similar to these established recognition sites are not present in Lem8 nor is there one resembling those in other nonphosphorylated binding targets of 14-3-3 such as GPlb-a (Gu and Du, 1998), p75NTR-associated cell death executor (NADE) (Kimura et al., 2001) or CLIC4 (Suginta et al., 2001).

Two lines of evidence suggest that $14-3-3 \zeta$ recognizes a coiled coil motif in the amino terminal portion of Lem8. First, deletion of as few as 25 residues from the amino terminus end of Lem8 abolished its interaction with 14-3-3ろ (Fig. 2D). Second, the integrity of a predicted coiled coil motif in the amino terminal portion of Lem8 is required for its binding to the regulatory protein (Fig. 5). Coiled coil motifs have long been known to be important for protein-protein interaction but its involvement in binding 14-3-3 has not yet been established. The binding of 14-3-3 to TRIM25 had been suggested to be mediated by recognizing a coiled coil domain, but the mechanism of such binding or whether phosphorylation is required remains unclear (Gupta et al., 2019). Future study,

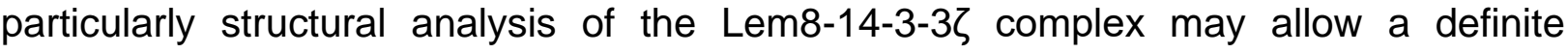
identification of the region in Lem8 recognized by $14-3-3 \zeta$, which will surely shed light on the additional features of the sequences recognizable by this imporant regulatory protein.

The self-cleavage of Lem8 has allowed us to identify its recognition sequence and several candidate cellular targets. One unexpected observation is that mutations in the identified recogniztion element reduced but did not abolished self-cleavage (Fig. 3D). Thus, the primary sequence may not the only factor that dictates the specificity of Lem8 in substrate recognition. Other factors such as the overall structure of substrates may contribute to the configuration of the recognition site. The low level of specificity in cleavage site selection may allow Lem8 to more effectively bring down the cellular level of its targets, which may explain the requirement of $14-3-3 \zeta$ for its activity. If a host co-factor is not needed for its activity, Lem8 may cleave itself or even other proteins in $L$. 
pneumophila cells. For Lem8, self-cleavage in the absence of $14-3-3 \zeta$ in bacterial cells will be disastrous because the cleaved product will lose the portion of the protein that harbors translocation signals recognized by the Dot/lcm system (Luo and Isberg, 2004; Nagai et al., 2005). Likewise, the requirement of CaM by the Dot/lcm effector SidJ to inhibit the activity of members of the SidE family is to ensure that such inhibition does not occur in bacterial cells (Bhogaraju et al., 2019; Black et al., 2019; Gan et al., 2019; Sulpizio et al., 2019). The promiscuity in cleavage site recognition by Lem8 is also supported by the observation that this protease appears to cleave Phldb2 at multiple sites (Figs. 4 and S5).

Interference with host cell motility appears to be a common strategy used by bacterial pathogens. For example, Salmonella enterica Typhimurium inhibits the migration of infected macrophages and dendritic cells in a process that requires its type III effector Ssel, which binds to IQGAP1, an important regulator of cell migration (McLaughlin et al., 2009). Similarly, the phosphatidylinositol phosphatase IpgD from Shigella flexneri contributes to the inhibition of chemokine-induced migration of human $T$ cells (Konradt et al., 2011). The observation that cells infected with the wild-type $L$. pneumophila or strain $\Delta / e m 8(\mathrm{pLem} 8)$ migrated significantly slower than those infected with the $\Delta / e m 8$ mutant or its complementation strain expressing the Lem8 $8_{\mathrm{C} 280 \mathrm{~A}}$ mutant suggests a role of Lem8 in cell mobility inhibition (Simon et al., 2014). Migration permits phagocytes including amoebae to move in response to chemotaxis cues, which likely will increase their chance to encounter cells that can recognize and engulf infected cells. Thus, cells with impaired motility are more likely to allow pathogens to complete their intracellular life cycle.

Akin to most L. pneumophila Dot/lcm effectors, Lem8 is not required for proficient bacterial intracellular growth in commonly used laboratory hosts such as $D$. discoideum. Lem8 may be required for the survival of the bacteria in some specific inhabits or other Dot/lcm effectors may substitute its role by distinct mechanisms, thus contributing to such inhibition. Future studies aiming at the identification and characterization of Dot/lcm effectors involved in attacking host cells motility will continue to provide insights 
521 into the mechanisms of not only bacterial virulence but also the regulation of eukaryotic 522 cell migration.

523 


\section{Bacterial strains, plasmids and cell culture}

E. coli strain DH5a was used for plasmid construction and strain BL21(DE3) or $\mathrm{XL1}$ blue was used for recombinant protein production and purification. All E. coli strains were grown on LB agar plates or in LB broth at $37^{\circ} \mathrm{C}$. For maintenance of plasmids in $E$. coli, antibiotics were added in media at the following concentrations: ampicillin,100 $\mu \mathrm{g} / \mathrm{mL}$; kanamycin, $30 \mu \mathrm{g} / \mathrm{mL}$. All L. pneumophila strains were derived from the Philadelphia 1 strain Lp02 and the $\operatorname{dotA}^{-}$mutant strain Lp03 (Berger and Isberg, 1993) and were listed in Table S2. L. pneumophila was cultured in $\mathrm{N}$-(2-acetamido)-2-aminoethanesulfonic acid buffered yeast extract medium (AYE) or on charcoal buffered yeast extract plates (CYE). When necessary, thymidine was added into AYE at a final concentration of $0.2 \mathrm{mg} / \mathrm{mL}$. pZL507 and its derivatives which allow expression of $\mathrm{His}_{6}$-tagged proteins (Xu et al., 2010) in L. pneumophila were maintained by thymidine autotrophic. Deletion of the Lem8 coding gene Ipg1290 (UniProtKB-Q5ZVZ8) from the genome of L. pneumophila was performed as described previously (Liu and Luo, 2007).

Plasmids used in this study are listed in Table S2. Genes were amplified by polymerase chain reactions (PCR) using Platinum ${ }^{\mathrm{TM}}$ SuperFi II Green PCR mix (Invitrogen, cat\# 12369050). The PCR product was digested with restriction enzymes (New England Biolabs, NEB), followed by ligated to linearized plasmid using T4 DNA ligase (NEB). For site-directed mutagenesis, plasmid was reacted with primer pairs designed to introduce the desired mutations using Quikchange kit (Agilent, cat\# 600670). After digestion with the restriction enzyme Dpnl (NEB, cat\# R0176), the products were transformed into the E. coli strain $\mathrm{DH} 5 \alpha$. All substitution mutants were verified by double strand DNA sequencing. The sequences of primers used for molecular cloning are listed in Table S2.

HEK293T and Hela cells purchased from ATCC were cultured in Dulbecco's modified minimal Eagle's medium (DMEM) supplemented with 10\% Fetal Bovine Serum (FBS). Bone marrow cells were isolated from 6- to 10-week-old female A/J mice

553 (GemPharmatech, Co., Ltd.) and were differentiated into BMDMs using L929-cell 
554 conditioned medium as described previously (Conover et al., 2003). PCR-based test 555 (Sigma, cat\# MP0025) was used to validate the absence of potential mycoplasma 556 contamination in all mammalian cell lines. pAPH-HA, a plasmid suitable for expressing proteins with an amino HA tag and a carboxyl Flag tag (Song et al., 2021) was used to express tagged proteins in mammalian cells.

\section{$\beta$-lactamase translocation assay}

To test the Dot/lcm-dependent translocation into host cells, Lem8 was cloned intro pXDC61m (Zhu et al., 2011) to generate s $\beta$-lactamase-Lem8 fusion. This plasmid was introduced wild-type or the $\operatorname{dot} A^{-}$mutant of $L$. pneumophila and the resulting strains were used to infect U937 cells at an MOI of 20 after 0.5 mM IPTG induction. One hour after infection, the CCF4-AM substrates (Invitrogen, Carlsbad, CA) were added into the medium and the cells were incubated for another $2 \mathrm{~h}$ at $25^{\circ} \mathrm{C}$, followed by image acquisition using an Olympus IX-83 fluorescence microscope. The translocation of Lem8 was assessed by calculating the percentage of cells emitting blue fluorescence.

\section{Yeast manipulation}

Unless otherwise indicated, yeast strains used in this study were derived from W303 (Thomas and Rothstein, 1989); yeast was grown at $30^{\circ} \mathrm{C}$ in yeast extract, peptone, dextrose medium (YPD) medium or in appropriate amino acid dropout synthetic media supplemented with $2 \%$ of glucose or galactose as the sole carbon source.

For assessment of inducible protein toxicity, Lem8 or its derivatives were cloned into pYES2/NTA (Invitrogen) in which their expression is driven by the galactose-inducible promoter. Yeast transformation was performed using the lithium acetate method (Gietz et al., 1995). After growing in selective liquid medium with $2 \%$ raffinose, yeast cultures were serially diluted (five-fold) and $10 \mu \mathrm{L}$ of each dilution was spotted onto selective plates containing glucose or galactose. Plates were incubated at $30^{\circ} \mathrm{C}$ for 3 days before image acquisition.

To screen Lem8-interacting protein(s), Gal4-based two-hybrid screening against the 
583

584

585

586

587

588

589

590

591

592

593

594

595

596

597

598

599

600

601

602

603

604

605

606

607

608

609

610

611

612

mouse cDNA library (Clontech) was performed as described before (Mitsuzawa et al., 2005). Briefly, Lem8 $8_{\text {c28os }}$ was inserted into pGBKT7 (Banga et al., 2007) to give pGBKLem8, which was transformed into the yeast strain PJ-64A (James et al., 1996) and the resulting strain was used for yeast two-hybrid screening. The mouse cDNA library was amplified in accordance with the manufacturer's instructions and the plasmid DNA was transformed into strain PJ-64A (pGBKLem8). Transformants were plated onto a selective synthetic medium lacking adenine, tryptophan, leucine, and histidine, colonies appeared on the selective medium were verified for interactions by reintroducing into strain PJ-64A (pGBKLem8) and inserts of those that maintained the interaction phenotype were sequenced to identify the interacting proteins.

To validate the interactions between 14-3-3 $\zeta$ and Lem8, its full-length gene was inserted into pGADGH (Banga et al., 2007) and the plasmids were introduced yeast strain PJ-64A (pGBKLem8). Yeast strains harboring the indicated plasmid combinations were streaked on $\mathrm{Leu}^{-}$and Trp' synthetic medium to select for plasmids and the transformants were transferred to Leu', Trp-, Ade-, and His medium to examine protein-protein interactions measured by cell growth.

\section{Antibodies and immunoblotting}

Polyclonal antibody against Lem8 were generated according to the protocol described before (Guide for the Care and Use of Laboratory Animals, 1996; J. Derrell Clark, 1997). Briefly, $1 \mathrm{mg}$ of emulsified $\mathrm{His}_{6}$-Lem8 with complete Freund's adjuvant was injected intracutaneously into a rabbit 4 times at 10-day intervals. Sera of the immunized rabbit containing Lem8-specific antibodies were used for affinity purification of IgG with an established protocol (Harlow, 1999).

Samples from cells or bacterial lysates were prepared by adding $5 \times$ SDS loading buffer and heated at $95^{\circ} \mathrm{C}$ for $10 \mathrm{~min}$. The soluble fraction of the lysates was resolved by SDS-PAGE, proteins were transferred onto polyvinylidene fluoride (PVDF) membranes (Pall Life Sciences). The membranes were blocking with 5\% nonfat milk for 30 min, followed by incubated with primary antibodies at the indicated dilutions: $\alpha-P h l d b 2$ (Sigma, cat\# HPA035147, 1:1000), a-HA (Sigma, cat\# H3663, 1:3000), a-Flag (Sigma, 
613 Cat\# F1804, 1: 3000), a-GFP (Proteintech, cat\# 50430-2-AP, 1:5000), a-GST 614 (Proteintech, cat\# 66001-2, 1:10000), a-His (Sigma, cat\# H1029, 1: 3,000), a-ICDH (1: 615 10,000) (Xu et al., 2010), a-Lem8 (1: 5,000), a-PGK (Abcam, cat\# ab113687, 1:2,500)

616

617

618

619

620

621

622

623

624

625

626

627

628

629

630

631

632

633

634

635

636

637

638

639

640

641

642 and $\alpha$-Tubulin (Bioworld, cat\# AP0064, 1:10,000). After washed 3 times, the membranes were incubated with appropriate HRP-labeled secondary antibodies and the signals were taken and analyzed by Tanon 5200 Chemiluminescent Imaging System.

\section{Transfection and immunoprecipitation}

When grown to approximately $80 \%$ confluence, HEK293T cells were transfected using Lipofectamine 3000 (Invitrogen, cat\# L3000150) according to the manufacturer's protocol. Twenty-four hours after transfection, cells were lysed using a lysis buffer (50 $\mathrm{mM}$ Tris- $\mathrm{HCl}, 150 \mathrm{mM} \mathrm{NaCl}, 0.5 \%$ Triton X-100, PH 7.5) for $10 \mathrm{~min}$ on ice, followed by centrifugation at $12,000 \mathrm{~g}$ at $4^{\circ} \mathrm{C}$ for $10 \mathrm{~min}$. Beads coated with Flag- (Sigma, cat\# F2426), HA- (Sigma, cat\# E6779) or GFP-specific antibodies (Sigma, cat\# G6539) were washed twice with lysis buffer and then mixed with the prepared cell supernatant. The mixture was incubated on a rotatory shaker at $4^{\circ} \mathrm{C}$ overnight. The resin was washed with the lysis buffer for five times, followed by boiling in the Laemmli buffer at $95^{\circ} \mathrm{C}$ for $10 \mathrm{~min}$ to release the bound Flag- or HA-tagged proteins. For proteins used in biochemical reactions, the Flag- or HA-tagged proteins were eluted with Flag peptide (Sigma, cat\# F4799) or HA peptide (Sigma, cat\# I2149), respectively.

\section{Protein expression and purification}

Lem8 and its mutants were amplified by PCR and cloned into pQE30 to express $\mathrm{His}_{6}$-tagged proteins. The plasmids were transformed into in E. coli strain XL1blue and grown in LB broth. When the cell density reached an $\mathrm{OD}_{600}$ of 0.8 , isopropyl- $\beta$-D-thiogalactopyranoside (IPTG) was added into the cultures at a final concentration of $0.2 \mathrm{mM}$ to induce the expression of target proteins for $14 \mathrm{~h}$ at $16^{\circ} \mathrm{C}$. Cells collected by centrifugation were re-suspended in a lysis buffer $(1 \times P B S, 2$ mM DTT and $1 \mathrm{mM} \mathrm{PMSF}$ ), and were lysed with a cell homogenizer (JN-mini, JNBIO, Guangzhou, China). The lysates were centrifugated at $20,000 \mathrm{~g}$ for $30 \mathrm{~min}$ at $4^{\circ} \mathrm{C}$ twice to remove cell 
643 debris. The supernatant was incubated with $\mathrm{Ni}^{2+}-\mathrm{NTA}$ beads (QIAGEN) at $4^{\circ} \mathrm{C}$ for $1 \mathrm{~h}$, 644 followed by washed with $50 x$ bed volumes of $20 \mathrm{mM}$ imidazole to remove unbound 645 proteins. The $\mathrm{His}_{6}$-tagged proteins were eluted with $250 \mathrm{mM}$ imidazole in PBS buffer. 646 Purified proteins were dialyzed in a storage buffer $(30 \mathrm{mM} \mathrm{NaCl}, 20 \mathrm{mM}$ Tris, $10 \%$ 647 glycerol, $\mathrm{pH} 7.5$ ) overnight at $4^{\circ} \mathrm{C}$ and then stored at $-80^{\circ} \mathrm{C}$.

$64814-3-3 \zeta$ and its homologous genes were cloned into pGEX6p-1 to express 649 GST-tagged proteins. The plasmids were transformed into E. coli strain BL21(DE3). 650 Protein expression induction and purification was carried out similarly with Glutathione Sepharose 4B (GE Healthcare) beads. The resin was collected and washed for with wash buffer (lysis buffer plus $200 \mathrm{mM} \mathrm{NaCl}$ ). The GST-tagged proteins were eluted with $10 \mathrm{mM}$ glutathione and stored at $-80^{\circ} \mathrm{C}$ after dialysis.

\section{In vitro cleavage assays}

For auto-cleavage assays, $5 \mu \mathrm{g} \mathrm{His}{ }_{6}$-Lem8 or its mutants was incubated with or without $2.5 \mu \mathrm{g}$ 14-3-3弓 in $50 \mu \mathrm{l}$ reaction buffer (50 mM Tris, $150 \mathrm{mM} \mathrm{NaCl}, \mathrm{PH} 7.5$ ) at room temperature for the indicated time points. For substrate candidates cleavage, Flag-or HA- tagged proteins purified from HEK293T cells were added into reactions with or without Lem8 and 14-3-3ろ at room temperature for the indicated time. In each case, samples were analyzed by SDS-PAGE followed by immunoblotting or Coomassie brilliant blue staining.

\section{GST pulldown assay}

GST-14-3-3 3 or GST bound to Glutathione Sepharose 4B was incubated with His $_{6}$-Lem8 in a binding buffer $(50 \mathrm{mM}$ Tris, $137 \mathrm{mM} \mathrm{NaCl}, 13.7 \mathrm{mM} \mathrm{KCl})$ for $2 \mathrm{~h}$ at $4{ }^{\circ} \mathrm{C}$. After washing three times with the binding buffer, beads were boiled in the Laemmli buffer at $95^{\circ} \mathrm{C}$ for $10 \mathrm{~min}$ and the samples were resolved by SDS-PAGE. Proteins were detected by Coomassie brilliant blue staining. 
post-exponential growth phase $\left(O D_{600}=3.3-3.8\right)$. When necessary, complementation strains were induced by $0.1 \mathrm{mM}$ IPTG for another $4 \mathrm{~h}$ at $37^{\circ} \mathrm{C}$ before infection.

To determine intracellular bacterial growth, $D$. discoideum or BMDMs of $A / J$ mice were infected with relevant $L$. pneumophila at a multiplicity of infection (MOI) of $0.1 .2 \mathrm{~h}$ after adding the bacteria, the cells were washed using warm PBS to remove the extracellular bacteria. D. discoideum and BMDMs were maintained in $22^{\circ} \mathrm{C}$ and $37^{\circ} \mathrm{C}$, respectively. At the indicated time points, cells were lysed with $0.2 \%$ saponin and appropriately diluted lysates were plated on CYE plates. After 4-day incubation at $37^{\circ} \mathrm{C}$, the counts of bacterial colonies were calculated to evaluate the growth.

To determine the impact of the infection on cell migration, HEK293T cells transfected to express FcyRII receptor (Qiu et al., 2016) were infected with the indicated bacterial strains. $2 \mathrm{~h}$ after infection, cells were washed using warm PBS and were used for the wound healing assay.

To determine the cellular localization of Lem8 in infected cells, BMDMs were infected with relevant $L$. pneumophila strains at an $\mathrm{MOI}$ of 10 for $2 \mathrm{~h}$. The samples were immunostained as described earlier (Haenssler et al., 2015). Briefly, we washed the samples 3 times with PBS to remove extracellular bacteria, and fixed the cells with $4 \%$ paraformaldehyde at room temperature for $10 \mathrm{~min}$. After three times washes, cells were permeabilized using $0.1 \%$ Triton X-100 and then were blocked with $4 \%$ goat serum for 1 h. Samples were incubated with rat anti-Legionella antibodies $(1: 10,000)$ and rabbit anti-Lem8 antibodies $(1: 100)$ at $4^{\circ} \mathrm{C}$ overnight. followed by incubated with appropriate fluorescence-labeled secondary antibodies at room temperature for $1 \mathrm{~h}$. After stained by Hoechst 33342 (Invitrogen, cat\# H3570, 1:5000), samples were inspected using an Olympus IX-83 fluorescence microscope.

To detect the cleavage of endogenous Phldb2 by Lem8, Hela cells transfected to express mCherry-Lem8 or mCherry-Lem8 ${ }_{\mathrm{C} 280 \mathrm{~S}}$ were stained with Phldb2-specific antibodies (1:100) as described above. The images were taken using a Zeiss LSM 880 confocal microscope. The determine the impact on ectopically expressed Phldb2, mCherry-Lem8 or mutants each was co-transfected with GFP-Phldb2 into HEK293T cells seeded onto glass coverslips (Nest, cat\# 801001). Fixed samples were stained 
with Hoechst, cell images were acquired by a confocal microscope.

\section{Production of lentiviral particles and transduction}

For production of lentiviral particles carrying lem8 or its mutants, the gfp-lem8 fusion was inserted into pCDH-CMV-MCS-EF1a-Puro (System Biosciences, cat\# CD510B-1). The plasmids were co-transfected with pMD2.G (gift from Dr. Didier Trono, Addgene \#12259) and psPAX2 (gift from Dr. Didier Trono, Addgene \#12260) into HEK293T cells grown to about $70 \%$ confluence. Supernatant was collected after 48 hours incubation, followed by filtration with $0.45-\mu \mathrm{m}$ syringe filters. After measuring the titers using qPCR with the Lentivirus Titer Kit (abm, cat\# LV900), the packed lentiviral particles were used to infect newly prepared HEK293T cells at an MOI of 10. After incubation for 2 days, cells were sorted by $\mathrm{BD}$ Influx ${ }^{\mathrm{TM}}$ cell sorter to establish cell lines stably expressing the gene of interest.

\section{Mass spectrometry analysis of Lem8 self-cleavage site}

Recombinant $\mathrm{His}_{6}$-Lem8 was incubated with $\mathrm{His}_{6}-14-3-3 \zeta$ for $8 \mathrm{~h}$ and the samples were separated by SDS-PAGE. After Coomassie brilliant blue staining, bands corresponding full-length $\mathrm{His}_{6}$-Lem8 or cleaved were excised and subjected to in-gel digestion with trypsin. Peptides were loaded into a nano-LC system (EASY-nLC 1200, Thermo Scientific) coupled to an LTQ-Orbitrap mass spectrometer (Orbitrap Velos, Thermo Scientific). Peptides were separated in a capillary column $(75 \mu \mathrm{m} \times 15 \mathrm{~cm})$ packed with C18 resin (Michrom BioResources Inc., $4 \mu \mathrm{m}, 100 \AA$ ) with the following gradient: solvent B (100 ACN, 0.1\% FA) was started at $7 \%$ for 3 min and gradually raised to $35 \%$ in 40 min, then rapidly increased to $90 \%$ in 2 min and maintained for 10 min before column equilibration with $100 \%$ solvent $\mathrm{A}\left(97 \% \mathrm{H}_{2} \mathrm{O}, 3 \% \mathrm{ACN}, 0.1 \% \mathrm{FA}\right)$. The flow rate was set at $300 \mathrm{~nL} / \mathrm{min}$ and eluting peptides were directly analyzed in the mass spectrometer. Full-MS spectra were collected in the range of 350 to $1500 \mathrm{~m} / z$ and the top 10 most intense parent ions were submitted to fragmentation in a data-dependent mode using collision-induced dissociation (CID) with the max injection time of 10 milliseconds. MS/MS spectra were searched against the L. pneumophila (strain Philadelphia 1) 
database downloaded from UniProt using Mascot (Matrix Science Inc.). The signals of Lem8 tryptic peptides were compared between full-length and cleaved samples to narrow down the potential cleavage site(s) within specific peptides, cleaved Lem8 semi-tryptic peptides were inspected manually.

\section{Wound healing assay}

Wound healing assays were performed as previously described (Liang et al., 2007). Briefly, HEK293T cells or Raw264.7 cells were seeded into 6-well plates and incubated until the confluency reached about $90 \%$. The cell monolayer was scraped in a straight line using a p200 pipet tip to create a "wound", followed by washing with growth medium to remove the debris. Reduced-serum medium (1\% serum) was added and the cells were placed back in a $37^{\circ} \mathrm{C}$ incubator. $2 \mathrm{~h}, 24 \mathrm{~h}$ and $48 \mathrm{~h}$ after making the scratch, images of the cell monolayer wound were taken using an Olympus IX-83 fluorescence microscope. For each image, distances between one side of the wound and the other were quantitated by Image $\mathrm{J}$ (http://rsb.info.nih.gov/ij/). The wound healing rate was calculated by the following formula: \% wound healing $=(0 \mathrm{~h}$ distance $-24 \mathrm{~h}$ distance $) / 24$ $\mathrm{h}$ distance $\times 100$.

\section{Data quantitation, statistical analyses}

All data were represented as mean \pm standard deviation (SD). Student's $t$-test was applied to analyze the statistical difference between two groups each with at least three independent samples.

\section{Acknowledgements}

The authors thank Dr. Shaohua Wang for plasmids, the study was funded in part by Jilin Science and Technology Agency grant 20200403117SF (LS), 20200901010SF (DL), National Natural Science Foundation of China grant 21974002 (XL), Beijing Municipal Natural Science Foundation grant 5202012 (XL), and the National Institutes of Health grant R01Al127465 (ZQL). 


\section{Author contributions}

764 LS, DL, ZQL, YL and YT conceived the projects, LS, YL, YT, JL, DH, and YZ performed 765 the experiments. KY and XL performed the mass spectrometric analysis. LS, DL, YT, YL, $766 \mathrm{XL}$, and $\mathrm{ZQL}$ analyzed data. SL drafted the first version of the manuscript, and $\mathrm{ZQL}$ 767 revised the manuscript with input from all authors. 
Arasaki, K., Mikami, Y., Shames, S.R., Inoue, H., Wakana, Y., and Tagaya, M. (2017). Legionella effector Lpg1137 shuts down ER-mitochondria communication through cleavage of syntaxin 17. Nat Commun 8, 15406. 10.1038/ncomms15406. Astro, V., Chiaretti, S., Magistrati, E., Fivaz, M., and de Curtis, I. (2014). Liprin-alpha1, ERC1 and LL5 define polarized and dynamic structures that are implicated in cell migration. J Cell Sci 127, 3862-3876. 10.1242/jcs.155663. Legionella pneumophila inhibits macrophage apoptosis by targeting pro-death members of the Bcl2 protein family. Proc Natl Acad Sci U S A 104, 5121-5126. 10.1073/pnas.0611030104.

Berger, K.H., and Isberg, R.R. (1993). Two distinct defects in intracellular growth complemented by a single genetic locus in Legionella pneumophila. Mol Microbiol 7, 7-19. 10.1111/j.1365-2958.1993.tb01092.x.

Bhogaraju, S., Bonn, F., Mukherjee, R., Adams, M., Pfleiderer, M.M., Galej, W.P., Matkovic, V., Lopez-Mosqueda, J., Kalayil, S., Shin, D., and Dikic, I. (2019). Inhibition of bacterial ubiquitin ligases by SidJ-calmodulin catalysed glutamylation. Nature 572 , 382-386. 10.1038/s41586-019-1440-8.

Black, M.H., Osinski, A., Gradowski, M., Servage, K.A., Pawlowski, K., Tomchick, D.R., and Tagliabracci, V.S. (2019). Bacterial pseudokinase catalyzes protein polyglutamylation to inhibit the SidE-family ubiquitin ligases. Science 364, 787-792. 10.1126/science.aaw7446.

791

Burkhard, P., Stetefeld, J., and Strelkov, S.V. (2001). Coiled coils: a highly versatile protein folding motif. Trends Cell Biol 11, 82-88. 10.1016/s0962-8924(00)01898-5. Burstein, D., Amaro, F., Zusman, T., Lifshitz, Z., Cohen, O., Gilbert, J.A., Pupko, T., Shuman, H.A., and Segal, G. (2016). Genomic analysis of 38 Legionella species identifies large and diverse effector repertoires. Nat Genet 48, 167-175. 10.1038/ng.3481.

Burstein, D., Zusman, T., Degtyar, E., Viner, R., Segal, G., and Pupko, T. (2009). Genome-scale identification of Legionella pneumophila effectors using a machine learning approach. PLoS Pathog 5, e1000508. 10.1371/journal.ppat.1000508. Cazalet, C., Rusniok, C., Bruggemann, H., Zidane, N., Magnier, A., Ma, L., Tichit, M., Jarraud, S., Bouchier, C., Vandenesch, F., et al. (2004). Evidence in the Legionella pneumophila genome for exploitation of host cell functions and high genome plasticity. Nat Genet 36, 1165-1173. 10.1038/ng1447.

804

805 Charpentier, X., Gabay, J.E., Reyes, M., Zhu, J.W., Weiss, A., and Shuman, H.A. (2009). Chemical genetics reveals bacterial and host cell functions critical for type IV effector translocation by Legionella pneumophila. PLoS Pathog 5, e1000501. 10.1371/journal.ppat.1000501. Cheng, M.I., Chen, C., Engstrom, P., Portnoy, D.A., and Mitchell, G. (2018). Actin-based motility allows Listeria monocytogenes to avoid autophagy in the macrophage cytosol. Cell Microbiol 20, e12854. 10.1111/cmi.12854.

811 Chisholm, S.T., Dahlbeck, D., Krishnamurthy, N., Day, B., Sjolander, K., and Staskawicz, 812 B.J. (2005). Molecular characterization of proteolytic cleavage sites of the 813 Pseudomonas syringae effector AvrRpt2. Proc Natl Acad Sci U S A 102, 2087-2092. 
10.1073/pnas.0409468102.

Choy, A., Dancourt, J., Mugo, B., O'Connor, T.J., Isberg, R.R., Melia, T.J., and Roy, C.R. (2012). The Legionella effector RavZ inhibits host autophagy through irreversible Atg8 deconjugation. Science 338, 1072-1076. 10.1126/science.1227026.

Cohen, M.S., and Chang, P. (2018). Insights into the biogenesis, function, and regulation of ADP-ribosylation. Nat Chem Biol 14, 236-243. 10.1038/nchembio.2568.

Conover, G.M., Derre, I., Vogel, J.P., and Isberg, R.R. (2003). The Legionella pneumophila LidA protein: a translocated substrate of the Dot/lcm system associated with maintenance of bacterial integrity. Mol Microbiol 48, 305-321. 10.1046/j.1365-2958.2003.03400.x.

Cunha, B.A., Burillo, A., and Bouza, E. (2016). Legionnaires' disease. Lancet 387, 376-385. 10.1016/S0140-6736(15)60078-2.

De leso, M.L., and Pei, J.V. (2018). An accurate and cost-effective alternative method for measuring cell migration with the circular wound closure assay. Biosci Rep 38 . 10.1042/BSR20180698.

Eichinger, L., Pachebat, J.A., Glockner, G., Rajandream, M.A., Sucgang, R., Berriman, M., Song, J., Olsen, R., Szafranski, K., Xu, Q., et al. (2005). The genome of the social amoeba Dictyostelium discoideum. Nature 435, 43-57. 10.1038/nature03481.

Franco, I.S., Shohdy, N., and Shuman, H.A. (2012). The Legionella pneumophila effector VipA is an actin nucleator that alters host cell organelle trafficking. PLoS Pathog 8, e1002546. 10.1371/journal.ppat.1002546.

Gabler, F., Nam, S.Z., Till, S., Mirdita, M., Steinegger, M., Soding, J., Lupas, A.N., and Alva, V. (2020). Protein Sequence Analysis Using the MPI Bioinformatics Toolkit. Curr Protoc Bioinformatics 72, e108. 10.1002/cpbi.108.

Gan, N., Zhen, X., Liu, Y., Xu, X., He, C., Qiu, J., Liu, Y., Fujimoto, G.M., Nakayasu, E.S., Zhou, B., et al. (2019). Regulation of phosphoribosyl ubiquitination by a calmodulin-dependent glutamylase. Nature 572, 387-391. 10.1038/s41586-019-1439-1. Gaspar, A.H., and Machner, M.P. (2014). VipD is a Rab5-activated phospholipase A1 that protects Legionella pneumophila from endosomal fusion. Proc Natl Acad Sci U S A 111, 4560-4565. 10.1073/pnas.1316376111.

Ge, J., Xu, H., Li, T., Zhou, Y., Zhang, Z., Li, S., Liu, L., and Shao, F. (2009). A Legionella type IV effector activates the NF-kappaB pathway by phosphorylating the IkappaB family of inhibitors. Proc Natl Acad Sci U S A 106, 13725-13730. 10.1073/pnas.0907200106.

Gietz, R.D., Schiestl, R.H., Willems, A.R., and Woods, R.A. (1995). Studies on the transformation of intact yeast cells by the LiAc/SS-DNA/PEG procedure. Yeast 11, 355-360. 10.1002/yea.320110408.

Gomez-Valero, L., Rusniok, C., Jarraud, S., Vacherie, B., Rouy, Z., Barbe, V., Medigue, C., Etienne, J., and Buchrieser, C. (2011). Extensive recombination events and horizontal gene transfer shaped the Legionella pneumophila genomes. BMC Genomics 12, 536. 10.1186/1471-2164-12-536.

Grieshaber, S.S., Grieshaber, N.A., and Hackstadt, T. (2003). Chlamydia trachomatis uses host cell dynein to traffic to the microtubule-organizing center in a p50 dynamitin-independent process. J Cell Sci 116, 3793-3802. 10.1242/jcs.00695.

$\mathrm{Gu}, \mathrm{M}$., and Du, X. (1998). A novel ligand-binding site in the zeta-form 14-3-3 protein recognizing the platelet glycoprotein Ibalpha and distinct from the c-Raf-binding site. $J$ 
Biol Chem 273, 33465-33471. 10.1074/jbc.273.50.33465.

Guide for the Care and Use of Laboratory Animals. (1996). (The National Academy of Sciences).

Guo, Z., Stephenson, R., Qiu, J., Zheng, S., and Luo, Z.Q. (2014). A Legionella effector modulates host cytoskeletal structure by inhibiting actin polymerization. Microbes Infect 16, 225-236. 10.1016/j.micinf.2013.11.007.

Gupta, S., Yla-Anttila, P., Sandalova, T., Sun, R., Achour, A., and Masucci, M.G. (2019). 14-3-3 scaffold proteins mediate the inactivation of trim25 and inhibition of the type I interferon response by herpesvirus deconjugases. PLoS Pathog 15, e1008146. 10.1371/journal.ppat.1008146.

Haenssler, E., Ramabhadran, V., Murphy, C.S., Heidtman, M.I., and Isberg, R.R. (2015). Endoplasmic Reticulum Tubule Protein Reticulon 4 Associates with the Legionella pneumophila Vacuole and with Translocated Substrate Ceg9. Infect Immun 83, 3479-3489. 10.1128/IAI.00507-15.

Harlow, E.L., D. (1999). Using Antibodies: A Laboratory Manual. Cold Spring Harbor Lab. Press, Plainview, NY, 311-343.

He, L., Lin, Y., Ge, Z.H., He, S.Y., Zhao, B.B., Shen, D., He, J.G., and Lu, Y.J. (2019). The Legionella pneumophila effector WipA disrupts host F-actin polymerisation by hijacking phosphotyrosine signalling. Cell Microbiol 21, e13014. 10.1111/cmi.13014. Henriksson, M.L., Francis, M.S., Peden, A., Aili, M., Stefansson, K., Palmer, R., Aitken, A., and Hallberg, B. (2002). A nonphosphorylated 14-3-3 binding motif on exoenzyme S that is functional in vivo. Eur $J$ Biochem 269, 4921-4929. 10.1046/j.1432-1033.2002.03191.x.

Huang, L., Boyd, D., Amyot, W.M., Hempstead, A.D., Luo, Z.Q., O'Connor, T.J., Chen, C., Machner, M., Montminy, T., and Isberg, R.R. (2011). The E Block motif is associated with Legionella pneumophila translocated substrates. Cell Microbiol 13, 227-245. 10.1111/j.1462-5822.2010.01531.x.

Iwai, K. (2021). Discovery of linear ubiquitination, a crucial regulator for immune signaling and cell death. FEBS J 288, 1060-1069. 10.1111/febs.15471.

J. Derrell Clark, G.F.G., Janet C. Gonder, Michale E. Keeling, Dennis F. Kohn (1997). The 1996 Guide for the Care and Use of Laboratory Animals. ILAR 38, 41-48.

James, P., Halladay, J., and Craig, E.A. (1996). Genomic libraries and a host strain designed for highly efficient two-hybrid selection in yeast. Genetics 144, 1425-1436.

Jones, M.C., Zha, J., and Humphries, M.J. (2019). Connections between the cell cycle, cell adhesion and the cytoskeleton. Philos Trans R Soc Lond B Biol Sci 374, 20180227. 10.1098/rstb.2018.0227.

Kagan, J.C., and Roy, C.R. (2002). Legionella phagosomes intercept vesicular traffic from endoplasmic reticulum exit sites. Nat Cell Biol 4, 945-954. 10.1038/ncb883.

Kapust, R.B., Tozser, J., Fox, J.D., Anderson, D.E., Cherry, S., Copeland, T.D., and Waugh, D.S. (2001). Tobacco etch virus protease: mechanism of autolysis and rational design of stable mutants with wild-type catalytic proficiency. Protein Eng 14, 993-1000. 10.1093/protein/14.12.993.

Kim, S.W., Ihn, K.S., Han, S.H., Seong, S.Y., Kim, I.S., and Choi, M.S. (2001). Microtubule- and dynein-mediated movement of Orientia tsutsugamushi to the microtubule organizing center. Infect Immun 69, 494-500. 
10.1128/IAI.69.1.494-500.2001.

Kimura, M.T., Irie, S., Shoji-Hoshino, S., Mukai, J., Nadano, D., Oshimura, M., and Sato, T.A. (2001). 14-3-3 is involved in p75 neurotrophin receptor-mediated signal transduction. J Biol Chem 276, 17291-17300. 10.1074/jbc.M005453200.

Konradt, C., Frigimelica, E., Nothelfer, K., Puhar, A., Salgado-Pabon, W., di Bartolo, V., Scott-Algara, D., Rodrigues, C.D., Sansonetti, P.J., and Phalipon, A. (2011). The Shigella flexneri type three secretion system effector $\operatorname{lpg} D$ inhibits $T$ cell migration by manipulating host phosphoinositide metabolism. Cell Host Microbe 9, 263-272. 10.1016/j.chom.2011.03.010.

Krachler, A.M., Woolery, A.R., and Orth, K. (2011). Manipulation of kinase signaling by bacterial pathogens. J Cell Biol 195, 1083-1092. 10.1083/jcb.201107132.

Kubori, T., and Galan, J.E. (2003). Temporal regulation of salmonella virulence effector function by proteasome-dependent protein degradation. Cell 115, 333-342. 10.1016/s0092-8674(03)00849-3.

Lansbergen, G., Grigoriev, I., Mimori-Kiyosue, Y., Ohtsuka, T., Higa, S., Kitajima, I., Demmers, J., Galjart, N., Houtsmuller, A.B., Grosveld, F., and Akhmanova, A. (2006). CLASPs attach microtubule plus ends to the cell cortex through a complex with LL5beta. Dev Cell 11, 21-32. 10.1016/j.devcel.2006.05.012.

Li, Q., and Verma, I.M. (2002). NF-kappaB regulation in the immune system. Nat Rev Immunol 2, 725-734. 10.1038/nri910.

Liang, C.C., Park, A.Y., and Guan, J.L. (2007). In vitro scratch assay: a convenient and inexpensive method for analysis of cell migration in vitro. Nat Protoc 2, 329-333. 10.1038/nprot.2007.30.

Liu, J., Zheng, Q., Deng, Y., Cheng, C.S., Kallenbach, N.R., and Lu, M. (2006). A seven-helix coiled coil. Proc Natl Acad Sci U S A 103, 15457-15462. 10.1073/pnas.0604871103.

Liu, Y., and Luo, Z.Q. (2007). The Legionella pneumophila effector SidJ is required for efficient recruitment of endoplasmic reticulum proteins to the bacterial phagosome. Infect Immun 75, 592-603. 10.1128/IAI.01278-06.

Liu, Y., Zhu, W., Tan, Y., Nakayasu, E.S., Staiger, C.J., and Luo, Z.Q. (2017). A Legionella Effector Disrupts Host Cytoskeletal Structure by Cleaving Actin. PLoS Pathog 13, e1006186. 10.1371/journal.ppat.1006186.

Luo, Z.Q., and Isberg, R.R. (2004). Multiple substrates of the Legionella pneumophila Dot/lcm system identified by interbacterial protein transfer. Proc Natl Acad Sci U S A 101, 841-846. 10.1073/pnas.0304916101.

Ma, J., He, Y., Hu, B., and Luo, Z.Q. (2013). Genome Sequence of an Environmental Isolate of the Bacterial Pathogen Legionella pneumophila. Genome Announc 1. 10.1128/genomeA.00320-13.

McLaughlin, L.M., Govoni, G.R., Gerke, C., Gopinath, S., Peng, K., Laidlaw, G., Chien, Y.H., Jeong, H.W., Li, Z., Brown, M.D., et al. (2009). The Salmonella SPI2 effector Ssel mediates long-term systemic infection by modulating host cell migration. PLoS Pathog 5 , e1000671. 10.1371/journal.ppat.1000671.

Michard, C., Sperandio, D., Bailo, N., Pizarro-Cerda, J., LeClaire, L., Chadeau-Argaud, E., Pombo-Gregoire, I., Hervet, E., Vianney, A., Gilbert, C., et al. (2015). The Legionella Kinase LegK2 Targets the ARP2/3 Complex To Inhibit Actin Nucleation on Phagosomes 
and Allow Bacterial Evasion of the Late Endocytic Pathway. mBio 6, e00354-00315. 10.1128/mBio.00354-15.

Mitsuzawa, H., Kimura, M., Kanda, E., and Ishihama, A. (2005). Glyceraldehyde-3-phosphate dehydrogenase and actin associate with RNA polymerase II and interact with its Rpb7 subunit. FEBS Lett 579, 48-52. 10.1016/j.febslet.2004.11.045.

Morrison, D.K. (2009). The 14-3-3 proteins: integrators of diverse signaling cues that impact cell fate and cancer development. Trends Cell Biol 19, 16-23. 10.1016/j.tcb.2008.10.003.

Mukherjee, S., Keitany, G., Li, Y., Wang, Y., Ball, H.L., Goldsmith, E.J., and Orth, K. (2006). Yersinia YopJ acetylates and inhibits kinase activation by blocking phosphorylation. Science 312, 1211-1214. 10.1126/science.1126867.

Muslin, A.J., Tanner, J.W., Allen, P.M., and Shaw, A.S. (1996). Interaction of 14-3-3 with signaling proteins is mediated by the recognition of phosphoserine. Cell $84,889-897$. 10.1016/s0092-8674(00)81067-3.

Nagai, H., Cambronne, E.D., Kagan, J.C., Amor, J.C., Kahn, R.A., and Roy, C.R. (2005). A C-terminal translocation signal required for Dot/lcm-dependent delivery of the Legionella RalF protein to host cells. Proc Natl Acad Sci U S A 102, 826-831. 10.1073/pnas.0406239101.

Paranavitane, V., Coadwell, W.J., Eguinoa, A., Hawkins, P.T., and Stephens, L. (2003). LL5beta is a phosphatidylinositol $(3,4,5)$-trisphosphate sensor that can bind the cytoskeletal adaptor, gamma-filamin. J Biol Chem 278, 1328-1335. 10.1074/jbc.M208352200.

Pearson, J.S., Giogha, C., Muhlen, S., Nachbur, U., Pham, C.L., Zhang, Y., Hildebrand, J.M., Oates, C.V., Lung, T.W., Ingle, D., et al. (2017). EspL is a bacterial cysteine protease effector that cleaves RHIM proteins to block necroptosis and inflammation. Nat Microbiol 2, 16258. 10.1038/nmicrobiol.2016.258.

Pennington, K.L., Chan, T.Y., Torres, M.P., and Andersen, J.L. (2018). The dynamic and stress-adaptive signaling hub of 14-3-3: emerging mechanisms of regulation and context-dependent protein-protein interactions. Oncogene 37, 5587-5604. 10.1038/s41388-018-0348-3.

Petosa, C., Masters, S.C., Bankston, L.A., Pohl, J., Wang, B., Fu, H., and Liddington, R.C. (1998). 14-3-3zeta binds a phosphorylated Raf peptide and an unphosphorylated peptide via its conserved amphipathic groove. J Biol Chem 273, 16305-16310. 10.1074/jbc.273.26.16305.

Qiu, J., and Luo, Z.Q. (2017). Legionella and Coxiella effectors: strength in diversity and activity. Nat Rev Microbiol 15, 591-605. 10.1038/nrmicro.2017.67.

Qiu, J., Sheedlo, M.J., Yu, K., Tan, Y., Nakayasu, E.S., Das, C., Liu, X., and Luo, Z.Q. (2016). Ubiquitination independent of E1 and E2 enzymes by bacterial effectors. Nature 533, 120-124. 10.1038/nature17657.

Richards, A.M., Von Dwingelo, J.E., Price, C.T., and Abu Kwaik, Y. (2013). Cellular microbiology and molecular ecology of Legionella-amoeba interaction. Virulence 4, 307-314. 10.4161/viru.24290.

Rodriguez-Herva, J.J., Gonzalez-Melendi, P., Cuartas-Lanza, R., Antunez-Lamas, M., Rio-Alvarez, I., Li, Z., Lopez-Torrejon, G., Diaz, I., Del Pozo, J.C., Chakravarthy, S., et al. 
(2012). A bacterial cysteine protease effector protein interferes with photosynthesis to suppress plant innate immune responses. Cell Microbiol 14, 669-681. 10.1111/j.1462-5822.2012.01749.x.

Rothmeier, E., Pfaffinger, G., Hoffmann, C., Harrison, C.F., Grabmayr, H., Repnik, U., Hannemann, M., Wolke, S., Bausch, A., Griffiths, G., et al. (2013). Activation of Ran GTPase by a Legionella effector promotes microtubule polymerization, pathogen vacuole motility and infection. PLoS Pathog 9, e1003598. 10.1371/journal.ppat.1003598.

Schoch, C.L., Ciufo, S., Domrachev, M., Hotton, C.L., Kannan, S., Khovanskaya, R., Leipe, D., McVeigh, R., O'Neill, K., Robbertse, B., et al. (2020). NCBI Taxonomy: a comprehensive update on curation, resources and tools. Database (Oxford) 2020. $10.1093 /$ database/baaa062.

Segal, G. (2013). The Legionella pneumophila two-component regulatory systems that participate in the regulation of Icm/Dot effectors. Curr Top Microbiol Immunol 376, 35-52. 10.1007/82_2013_346.

Shalini, S., Dorstyn, L., Dawar, S., and Kumar, S. (2015). Old, new and emerging functions of caspases. Cell Death Differ 22, 526-539. 10.1038/cdd.2014.216.

Shao, F., Golstein, C., Ade, J., Stoutemyer, M., Dixon, J.E., and Innes, R.W. (2003). Cleavage of Arabidopsis PBS1 by a bacterial type III effector. Science 301, 1230-1233. 10.1126/science.1085671.

Shao, F., Merritt, P.M., Bao, Z., Innes, R.W., and Dixon, J.E. (2002). A Yersinia effector and a Pseudomonas avirulence protein define a family of cysteine proteases functioning in bacterial pathogenesis. Cell 109, 575-588. 10.1016/s0092-8674(02)00766-3.

Shen, X., Banga, S., Liu, Y., Xu, L., Gao, P., Shamovsky, I., Nudler, E., and Luo, Z.Q. (2009). Targeting eEF1A by a Legionella pneumophila effector leads to inhibition of protein synthesis and induction of host stress response. Cell Microbiol 11, 911-926. 10.1111/j.1462-5822.2009.01301.x.

Simon, S., Wagner, M.A., Rothmeier, E., Muller-Taubenberger, A., and Hilbi, H. (2014). $\mathrm{Icm} /$ Dot-dependent inhibition of phagocyte migration by Legionella is antagonized by a translocated Ran GTPase activator. Cell Microbiol 16, 977-992. 10.1111/cmi.12258.

Soding, J., Biegert, A., and Lupas, A.N. (2005). The HHpred interactive server for protein homology detection and structure prediction. Nucleic Acids Res 33, W244-248. 10.1093/nar/gki408.

Song, L., Xie, Y., Li, C., Wang, L., He, C., Zhang, Y., Yuan, J., Luo, J., Liu, X., Xiu, Y., et al. (2021). The Legionella Effector SdjA Is a Bifunctional Enzyme That Distinctly Regulates Phosphoribosyl Ubiquitination. mBio, e0231621. 10.1128/mBio.02316-21.

Sturgill-Koszycki, S., and Swanson, M.S. (2000). Legionella pneumophila replication vacuoles mature into acidic, endocytic organelles. J Exp Med 192, 1261-1272. 10.1084/jem.192.9.1261.

Suginta, W., Karoulias, N., Aitken, A., and Ashley, R.H. (2001). Chloride intracellular channel protein CLIC4 (p64H1) binds directly to brain dynamin I in a complex containing actin, tubulin and 14-3-3 isoforms. Biochem J 359, 55-64. 10.1042/0264-6021:3590055. Sulpizio, A., Minelli, M.E., Wan, M., Burrowes, P.D., Wu, X., Sanford, E.J., Shin, J.H., Williams, B.C., Goldberg, M.L., Smolka, M.B., and Mao, Y. (2019). Protein polyglutamylation catalyzed by the bacterial calmodulin-dependent pseudokinase SidJ. 
Elife 8. 10.7554/eLife.51162.

Swanson, M.S., and Isberg, R.R. (1995). Association of Legionella pneumophila with the macrophage endoplasmic reticulum. Infect Immun 63, 3609-3620. 10.1128/IAI.63.9.3609-3620.1995.

Tan, Y., Arnold, R.J., and Luo, Z.Q. (2011). Legionella pneumophila regulates the small GTPase Rab1 activity by reversible phosphorylcholination. Proc Natl Acad Sci U S A 108, 21212-21217. 10.1073/pnas.1114023109.

Thomas, B.J., and Rothstein, R. (1989). Elevated recombination rates in transcriptionally active DNA. Cell 56, 619-630. 10.1016/0092-8674(89)90584-9.

Tian, Q., Feetham, M.C., Tao, W.A., He, X.C., Li, L., Aebersold, R., and Hood, L. (2004). Proteomic analysis identifies that 14-3-3zeta interacts with beta-catenin and facilitates its activation by Akt. Proc Natl Acad Sci U S A 101, 15370-15375. 10.1073/pnas.0406499101.

Wan, M., Wang, X., Huang, C., Xu, D., Wang, Z., Zhou, Y., and Zhu, Y. (2019). A bacterial effector deubiquitinase specifically hydrolyses linear ubiquitin chains to inhibit host inflammatory signalling. Nat Microbiol 4, 1282-1293. 10.1038/s41564-019-0454-1. Xu, L., Shen, X., Bryan, A., Banga, S., Swanson, M.S., and Luo, Z.Q. (2010). Inhibition of host vacuolar $\mathrm{H}_{+}$-ATPase activity by a Legionella pneumophila effector. PLoS Pathog 6, e1000822. 10.1371/journal.ppat.1000822.

Yarbrough, M.L., Li, Y., Kinch, L.N., Grishin, N.V., Ball, H.L., and Orth, K. (2009). AMPylation of Rho GTPases by Vibrio VopS disrupts effector binding and downstream signaling. Science 323, 269-272. 10.1126/science.1166382.

Zhang, Y., Li, S., Yang, Z., Shi, L., Yu, H., Salerno-Goncalves, R., Saint Fleur, A., and Feng, H. (2018). Cysteine Protease-Mediated Autocleavage of Clostridium difficile Toxins Regulates Their Proinflammatory Activity. Cell Mol Gastroenterol Hepatol 5, 611-625. 10.1016/j.jcmgh.2018.01.022.

Zhou, Y., and Zhu, Y. (2015). Diversity of bacterial manipulation of the host ubiquitin pathways. Cell Microbiol 17, 26-34. 10.1111/cmi.12384.

Zhu, W., Banga, S., Tan, Y., Zheng, C., Stephenson, R., Gately, J., and Luo, Z.Q. (2011). Comprehensive identification of protein substrates of the Dot/lcm type IV transporter of Legionella pneumophila. PLoS One 6, e17638. 10.1371/journal.pone.0017638. 
Fig. 1 Lem8 is a cysteine protease-like Dot/lcm effector toxic to yeast

1074

1075

1076

1077

1078

1079

1080

1081

1082

1083

1084

1085

1086

1087

1088

1089

1090

1091

1092

1093

1094

1095

1096

1097

1098

1099

1100

A. Alignment of Lem8 with several known cysteine proteases obtained by PSI-BLAST analysis. The strictly conserved catalytic residues are marked in red. Shown cysteine proteases are HopN1 and AvrpphB from P. syringae, YopT from Y. enterocolitica, and PfhB1 from P. multocida.

B. Lem8 is translocated into mammalian cells via the Dot/lcm transporter. U937 cells were infected with wild-type $L$. pneumophila or the $\operatorname{dot} A^{-}$mutant expressing the $\beta$-lactamase-Lem8 fusion. One hour after infection, the CCF4-AM fluorescence substrate was added into the cultures and the cells were incubated for another $2 \mathrm{~h}$ at room temperature before image acquisition. Cells emitting blue fluorescence signals were quantitated by counting at least 500 cells in each experiment done in triplicate. Results shown are mean \pm s.e. from one representative experiment.

C. Expression profile of lem8 in L. pneumophila grown in AYE broth supplemented with thymidine. Bacteria grown to stationary phase were diluted at 1:20 in fresh medium and subcultures were grown in a shaker. Bacterial growth was monitored by measuring $\mathrm{OD}_{600}$ at the indicated time points. Equal amounts of bacterial cells were lysed for measurement of Lem8 levels by immunoblotting with Lem8-specific antibodies. The metabolic protein isocitrate dehydrogenase (ICDH) was probed as loading control.

D. Lem8 is toxic to yeast in a manner that requires the predicted Cys-His-Asp motif. Yeast strains expressing Lem8 or the indicated mutants from the galactose-inducible promotor were serially diluted and spotted on the indicated media. The plates were incubated at $30^{\circ} \mathrm{C}$ for $48 \mathrm{~h}$ before image acquisition. The expression of Lem8 and its mutants induced by galactose were determined by immunoblotting with Lem8-specific antibodies. The 3-phosphoglycerate kinase (PGK) was detected as loading control.

\section{Fig. 2 The interactions between Lem8 and 14-3-3ろ}

A. Interactions between Lem8 and 14-3-3 3 detected by yeast two-hybrid assay. Yeast strains harboring the indicated constructs were streaked on Leu- and Trp- medium to 
select for plasmids (left) or on Leu, Trp', Ade', and His medium to assess the interactions (right). Images were acquired after $3-d$ incubation at $30^{\circ} \mathrm{C}$.

B. Lem8 and $14-3-3 \zeta$ form a protein complex in mammalian cells. Total lysates of HEK293T cells transfected with the indicated plasmid combinations were immunoprecipitated with a Flag-specific antibody (left panels) or GFP-specific antibodies (right panels), and the precipitates were probed with both Flag and GFP antibodies. Similar results were obtained from at least three independent experiments and the data shown here were from one representative experiment.

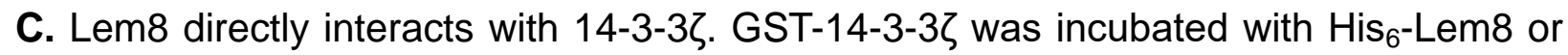
$\mathrm{His}_{6}$-Lem8 $8_{\mathrm{C} 280 \mathrm{~S}}$, and the potential protein complex was captured by glutathione beads for $1 \mathrm{~h}$ at $4^{\circ} \mathrm{C}$. After extensive washing, bound proteins were solubilized with SDS loading buffer, and proteins were detected by Coomassie brilliant blue staining after being resolved by SDS/PAGE. Similar results were obtained from at least three independent experiments and the data shown here were from one representative experiment.

D. Interactions between 14-3-3ろ and Lem8 deletion mutants. Lysates of 293T cells expressing Flag-14-3-3 3 and each of the HA-tagged deletion Lem8 were subjected to immunoprecipitation with the anti-HA antibody and the presence of $14-3-3 \zeta$ in the precipitates was probed with the Flag-specific antibody. Similar results were obtained from at least three independent experiments and the data shown here were from one representative experiment.

\section{Fig. 3 14-3-3 3 induces Lem8 to undergo self-cleavage}

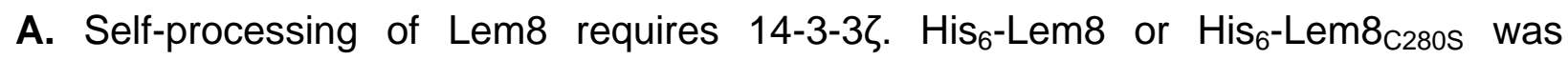
incubated with $\mathrm{His}_{6}-14-3-3 \zeta$ for $2 \mathrm{~h}$, proteins resolved by SDS-PAGE were detected by Coomassie brilliant blue staining. The cysteine protease inhibitor E64 was added to the indicated samples at a final concentration of $10 \mu \mathrm{M}$. Similar results were obtained from at least three independent experiments and the data shown here were from one representative experiment.

B. The 14-3-3 protein from D. discoideum induces the self-cleavage of Lem8. His 6 -Lem8 
was incubated with GST-14-3-3 or GST-14-3-3Dd for the indicated time and the mixtures separated by SDS-PAGE were detected by immunoblotting with antibodies specific for Lem8 and GST, respectively. Similar results were obtained from at least three independent experiments and the data shown here were from one representative experiment.

C. Determination of the self-cleavage site of Lem8. His 6 -Lem8 was incubated with His $_{6}-14-3-3 \zeta$ for $16 \mathrm{~h}$, proteins were resolved by SDS-PAGE, stained with Coomassie brilliant blue. Protein bands corresponding to full-length and cleaved Lem8 band was excised, digested with trypsin and analyzed by mass spectrometry. The detection of the semi-tryptic peptide - ${ }_{464} C E K A P Q P T P Q R Q_{476}$ - in cleaved samples suggested that the cleavage site lies between Gln476 and Arg477.

D. Mutations in cleavage site does not abolish Lem8 self-processing. Recombinant protein of Lem8 and the 4A mutant were each incubated with His-14-3-3 3 for $4 \mathrm{~h}$. Proteins resolved by SDS-PAGE were detected by Coomassie brilliant blue. Similar results were obtained from at least three independent experiments and the data shown here were from one representative experiment.

\section{Fig. 4 Lem8 cleaves Phldb2 in a manner that requires 14-3-3ろ.}

A. Multiple alignments of the self-cleavage site of Lem8 with potential targets in human cells identified by bioinformatic analysis. Identical residues are highlighted in red.

B. Lem8 reduces the protein levels of endogenous Phldb2 in mammalian cells. Lem8 and the indicated mutants were individually expressed in HEK293T cells by transfection. $24 \mathrm{~h}$ after transfection, the samples were resolved by SDS-PAGE and detected by immunoblotting with anti-Phldb2 antibodies. Tubulin was used as a loading control. Results shown were one representative from three independent experiments with similar results.

C. Lem8 cleaves exogenous Phldb2 in mammalian cells. HA and Flag tag were fused to the amino and carboxyl end of Phldb2 respectively and the double tagged protein was co-expressed in HEK293T cells with Lem8 or each of the mutants. $24 \mathrm{~h}$ after transfection, the samples were resolved by SDS-PAGE and probed by a HA-specific 
antibody and a Flag-specific antibody, respectively. Tubulin was detected as a loading control. Results shown were one representative from three independent experiments with similar results.

D. Lem8 alters the subcellular distribution of GFP fused to Phldb2. GFP was fused to the amino end of Phldb2 and the protein was co-expressed in HEK293T cells with mCherry-Lem8 or each of the mutants. $24 \mathrm{~h}$ after transfection, cells were fixed and nucleus were stained by Hoechst 33342. The fluorescence Images of GFP (green), mCherry (red) and Hoechst (blue) were acquired with a Zeiss LSM 880 confocal microscope. The percentage of cells with membrane Phldb2 was calculated in Phldb2 and Lem8 positive cells (Right panel). Bar, $10 \mu \mathrm{m}$.

E. $14-3-3 \zeta$ is required for the cleavage of Phldb2 by Lem8. HA-Phldb2-Flag was expressed in HEK293T cells, immunoprecipitated with a Flag-specific antibody, and eluted with $3 \times$ Flag peptides. Purified Phldb2 was incubated with $\mathrm{His}_{6}$-Lem8 or each of the mutants in reactions with or without $\mathrm{His}_{6}-14-3-3 \zeta$. Total proteins of all samples were resolved with SDS-PAGE, and probed by immunoblotting with a HA-specific antibody, a Flag-specific antibody and a His-specific antibody. Results shown were one representative from three independent experiments with similar results.

\section{Fig. 5 A Coiled coil motif in Lem8 is important for its interactions with 14-3-3ろ}

A. Lem8 harbors a putative coil motif. A predicted coiled coil motif located in the amino end of Lem8 (top panel). The sequence ranges from the $45^{\text {th }}$ residue to the $73^{\text {rd }}$ residue with a coiled-coil probability of $100 \%$ according to MARCOIL (lower panel, left). Replacement of $\mathrm{Leu}_{58}$ and $\mathrm{Glu}_{59}$ with glycine (highlighted in red) is predicted to reduce the coiled-coil probability to about $10 \%$ (lower panel, right).

B. The predicted coiled coil motif is critical for Lem8-mediated yeast toxicity. Yeast cells inducibly expressing Lem8 or mutant Lem8 ${ }_{\mathrm{GG}}$ were serially diluted and spotted onto the indicated media for $48 \mathrm{~h}$ (top panel). The expression of Lem8 and Lem8 ${ }_{\mathrm{GG}}$ was examined and PGK1 was probed as a loading control (lower panel).

C. Lem8 $8_{\mathrm{GG}}$ loses the capacity to cleave Phldb2 in mammalian cells. Lysates of HEK293T cells expressing Lem8 or Lem8 $8_{G G}$ were resolved by SDS-PAGE and detected by immunoblotting with antibodies specific for Phldb2 and HA, respectively. Tubulin was 
used as a loading control. Results shown were one representative from three independent experiments with similar results.

D. The predicted coiled coil motif is required for self-processing of Lem8. The indicated alleles of Lem8-GFP were individually expressed in HEK293T cells by transfection. Samples resolved by SDS-PAGE were detected by immunoblotting with GFP-specific antibodies. Results shown were one representative from three independent experiments with similar results.

E. Interactions between $14-3-3 \zeta$ and the Lem8 $8_{\mathrm{GG}}$ mutant. Lysates of $293 \mathrm{~T}$ cells expressing Flag-14-3-3ろ with HA-Lem8 or HA-Lem8 $8_{\mathrm{GG}}$ were subjected to immunoprecipitation with the anti-HA antibody and the presence of 14-3-3 $\zeta$ in the precipitates was probed with the Flag-specific antibody. Results shown were one representative from three independent experiments with similar results.

\section{Fig. 6 Auto-processed Lem8 retains the cysteine protease activity}

A. The auto-processed form of Lem8 cleaves Phldb2 in cells. HA-Phldb2-Flag was co-expressed in HEK293T cells with Lem8 or the indicated truncation mutants including the self-processed form, Lem8 $8_{\triangle \mathrm{C} 52 .} 24 \mathrm{~h}$ after transfection, the samples were resolved by SDS-PAGE and probed by a HA-specific antibody and a Flag-specific antibody. Tubulin was used as a loading control. Results shown were one representative from three independent experiments with similar results.

B. Lem8 ${ }_{\triangle \mathrm{C} 52}$ causes redistribution of GFP-Phldb2. Truncations of Lem8, including Lem8 ${ }_{\triangle N 25}$, Lem8 $8_{\triangle C 52}$ and Lem8 ${ }_{\triangle C 100}$ fused to mCherry was individually expressed in HEK293T cells with GFP-Phldb2. $24 \mathrm{~h}$ after transfection, the fluorescence images were acquired with a Zeiss LSM 880 confocal microscope. The percentage of cells with membrane Phldb2 was calculated in Phldb2 and Lem8 positive cells (Right panel). Bar, $10 \mu \mathrm{m}$.

C. The interaction between Lem8 ${ }_{\triangle C 52}$ and 14-3-3ろ. Total lysates of HEK293T cells transfected with indicated plasmid combinations were immunoprecipitated with antibodies specific for HA (left panel) or Flag (right), and the precipitates were probed with both HA and Flag antibodies. Similar results were obtained from at least three 
1221 independent experiments and the data shown here were from one representative 1222 experiment.

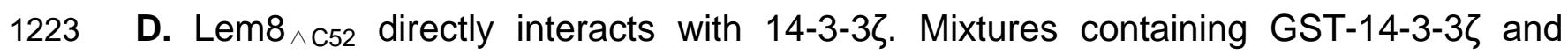
$1224 \mathrm{His}_{6}$-Lem8 ${ }_{\Delta \mathrm{C} 52}$ were incubated with glutathione beads for $1 \mathrm{~h}$ at $4^{\circ} \mathrm{C}$. After washing, 1225 samples resolved by SDS/PAGE were detected by Coomassie brilliant blue staining. 1226 Results shown were one representative from three independent experiments with similar 1227 results.

1228 E. The cleavage of Phldb2 by Lem8 ${ }_{\Delta \mathrm{C} 52}$ requires $14-3-3 \zeta$. Purified HA-Phldb2-Flag from HEK293T was incubated with $\mathrm{His}_{6}-$ Lem8 $_{\Delta \mathrm{C} 52}$ in reactions with or without His ${ }_{6}-14-3-3 \zeta$. Total proteins of all samples were resolved with SDS-PAGE, and probed by immunoblotting with antibody specific for $\mathrm{HA}$, Flag and $\mathrm{His}_{6}$, respectively. Results shown were one representative from three independent experiments with similar results.

Fig. 7 Lem8 contributes to cell migration inhibition by L. pneumophila

A. Establishment of cell lines stably expressing Lem8 or its enzymatically inactive mutant. HEK293T cells were transduced with lentiviral particles harboring the indicated plasmid at an MOI of 10 for two days, and the GFP-positive cells were isolated by a BD Influx ${ }^{\mathrm{TM}}$ cell sorter. Lysates of each cell lines were probed by immunoblotting with antibodies specific for Phldb2 or Lem8. Tubulin was used as a loading control.

B. Wound-healing scratch assay of the three stable cell lines. The three cell lines were individually seeded into 6 well plates. When reached confluency, cell monolayer of each cell lines was scratched using a pipette tip. Images of the wounds were captured at $2 \mathrm{~h}$, $24 \mathrm{~h}$ and $48 \mathrm{~h}$ after making the scratches using an Olympus IX-83 fluorescence microscope. Images of a representative experiment were shown (left panel). The wound healing rates from three independent experiments was quantitated by Image $\mathrm{J}$ (right panel).

C-D. Evaluation of the impact of Lem8 on cell migration in cells infected with $L$. pneumophila. HEK293T cells expressing the Fcyll receptor or Raw264.7 cells were infected with opsonized bacteria of the indicated L. pneumophila strains at an MOI of 50 for 2 h. After washes, the wound-healing scratch assay was performed to evaluate the 
1251 impact of infection on cell migration. Images of a representative experiment were shown 1252 (C, left panel) and the wound healing rate was analyzed by Image $\mathrm{J}(\mathrm{C}$, right panel). 1253 


\section{Legends for supplementary Figures}

Fig. S1 Sequence alignment of Lem8 with four bacterial cysteine protease effectors The strictly conserved residues were shown in dark purple background and the Cys-His-Asp motif are marked with white letters in a red background. HopN1 and AvrpphB are from $P$. syringae. YopT and PfhB1 are from Y. pestis and P. multocida, respectively.

Fig. S2 Lem8 is dispensable for intracellular growth of L. pneumophila

A. Subcellular distribution of Lem8. $2 \mathrm{~h}$ after infected with the indicated bacterial strains,

BMDMs were immunostained using anti-Legionella antibody to identify the bacterial vacuoles (green), followed by staining with the Lem8 specific antibody (red). The nucleus was stained using Hoechst 33342 (blue). Bar, $10 \mu \mathrm{m}$.

B. Intracellular growth of the $\Delta l e m 8$ strain in $D$. discoideum. D. discoideum were infected with the indicated bacterial strains at an $\mathrm{MOI}$ of 0.1 , and the intracellular growth was determined at a 24-h interval for $72 \mathrm{~h}$ (left panel). The expression and translocation of Lem8 in each strain was probed with Lem8 specific antibodies (right panel). ICDH and Tubulin were used as loading controls for bacterial and host cells, respectively. Similar results were obtained in three independent experiments.

C. Intracellular growth of $\Delta / e m 8$ strain in BMDMs. The bacterial strains were used to infect BMDMs at an $\mathrm{MOI}$ of 0.1 and the intracellular growth was monitored at the indicated time points (left panel). Similar results were obtained in three independent

Fig. S3 Phosphorylation of Lem8 is not required for 14-3-3ろ binding. Lysates of HEK293T cells expressing indicated HA tagged proteins were subjected to immunoprecipitation with agarose beads coated with the HA antibody. The precipitates, as well as $\mathrm{His}_{6}$-Lem8 purified from $E$ coli were resolved by SDS-PAGE and probed by immunoblotting with a pan phospho-serine/threonine antibody, the HA specific antibody and the $\mathrm{His}_{6}$-specific antibody, respectively. Results shown were one representative from three independent experiments with similar results. 
Fig. S4 Identification of the self-cleavage sites of Lem8.

A. Determination of the self-cleavage site of Lem8 by mass spectrometry. A diagram of the sequence containing the recognition site with the two diagnostic peptides used to determine the cleavage site (top panel). Protein bands corresponding to full-length and cleaved Lem8 band was excised ( lower left panel), digested with trypsin and analyzed by mass spectrometry. The semi-tryptic peptide $-\mathrm{L}_{464} \mathrm{CEKAPQPTPQRQ} \mathrm{Q}_{46}$ - is present in cleaved samples but not in samples of full-length Lem8, whereas the fragment -A $_{478}$ QSLSAETER ${ }_{487}$ - was only detected in samples of the full-length protein (lower right panel), supporting the notion that the cleavage site lies between GIn476 and Arg477 described in Fig. 3C.

B. Self-cleavage of Lem8 removes GFP fused to its carboxyl end. GFP was fused to the indicated alleles of Lem8 and the fusion proteins were individually expressed in HEK293T cells by transfection. Samples resolved by SDS-PAGE were detected by immunoblotting with GFP-specific antibodies. Results shown were one representative from three independent experiments with similar results.

C. The self-cleavage site of the 4A mutant. Protein bands from stained SDS-PAGE gels were excised and analyzed similarly as described in A. The tryptic fragment $\mathrm{A}_{468}$ PQPTPAAAAQSLSAETER ${ }_{487^{-}}$was detected only in samples prepared from the cleaved protein but not full-length protein. Identical results were obtained in multiple samples analyzed by two different mass spectrometry facilities.

\section{Fig. S5 Verification of Lem8-mediated cleavage of candidate proteins and its} cleavage of phldb2 at multiple sites A. Cleavage of substrate candidates by Lem8. Flag- or HA- tagged Rasgrp2, Pak6, Exoc8, Ankrd13B, Chkb, Ppp6R1, Kiaa1033, Gnal and Gpr61 expressed in HEK293T cells each was immunoprecipitated with antibodies specific for Flag or HA. Proteins eluted with $3 \times$ Flag or HA peptides were incubated with His-Lem8 and His ${ }_{6}-14-3-3 \zeta$. Samples resolved with SDS-PAGE were probed by immunoblotting with a Flag- or HAspecific antibody. Note that Flag- or HA-GPR61 did not express so it was not examined. Results shown were one representative from three independent experiments with similar results. 
B. Lem8 causes redistribution of Phldb2 in cells. Hela cells were transfected to express the indicated mCherry fusion proteins. $24 \mathrm{~h}$ after transfection, cells were fixed and immunostained with anti-Phldb2 antibodies. The nuclei were stained by Hoechst 33342 . Images were acquired with a Zeiss LSM 880 confocal microscope. Phldb2, green (GFP); Lem8 and its mutants, red (mCherry); nuclei, blue (Hoechst). The percentage of Phldb2 positive cells was calculated in Lem8 positive cells (Right panel). Bar, $10 \mu \mathrm{m}$.

C. Mutations were introduced into HA-Phldb2-Flag to replace residues $\operatorname{Arg}_{1111}$ and $\operatorname{Gln}_{1112}\left(P h l d b 2{ }_{A A 1}\right)$ or $\operatorname{Gln}_{1112}$ and $\operatorname{Arg}_{1113}\left(P h l d b 2{ }_{A A 2}\right)$ with alanine, respectively. The two mutants were co-expressed in HEK293T cells with Lem8 or Lem8c280s. Samples were resolved with SDS-PAGE, and probed by immunoblotting with the antibody specific to $\mathrm{HA}$ and Flag, respectively. Mutations in the cleavage site of Phldb2 cannot completely prevent its degradation by Lem8. Results shown were one representative from three independent experiments with similar results.

D. Lem8 removes the GFP tag fused to the amino end of Phldb2 deletion mutants. GFP was fused to the amino end of Phldb2 and the indicated truncation mutants. The fusion proteins were individually co-expressed with HA-Lem8 or HA-Lem8 ${ }_{\text {c280s }}$ in HEK293T cells by transfection. Samples resolved by SDS-PAGE were detected by immunoblotting with GFP-specific antibodies. Results shown were one representative from three independent experiments with similar results.

E. Cleavage of Phldb2 is undetectable during L. pneumophila infection. HEK293T cells transfected to express FcyRII receptor were infected with the indicated bacterial strains. $2 \mathrm{~h}$ after infection, the protein levels of Phldb2, as well as the translocation and expression of Lem8, were probed with the appropriate antibodies with Tubulin and ICDH as loading control, respectively. Results shown were one representative from three independent experiments with similar results. Bacterial strains: I, Non-infection; II, Lp02

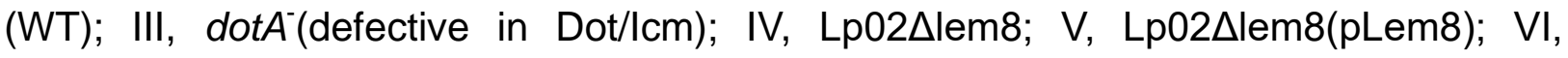
Lp02Alem8(pLem8 ${ }_{\text {c280s) }}$. cell migration 
1348 A. Overexpression of Phldb2 in 293T cells stably expressing Lem8. A HEK293T-derived 1349 cell line stably expressing Lem8 was transfected with empty vector or HA-Phldb2 for 18 $1350 \mathrm{~h}$, and the cell lysates were probed by immunoblotting with antibodies specific for 1351 Phldb2 or Lem8. Tubulin was used as a loading control. Results shown were one 1352 representative from three independent experiments with similar results.

1353 B. Wound-healing scratch assay of cells expressing Phldb2. $18 \mathrm{~h}$ after transfection, 1354 monolayers were scratched using a pipette tip. Images of the wounds were captured at $13552 \mathrm{~h}, 24 \mathrm{~h}$ and $48 \mathrm{~h}$, respectively. Results shown were from a representative of three 1356 independent experiments from which the quantitation of wound healing was obtained by 1357 Image J (right panel). 

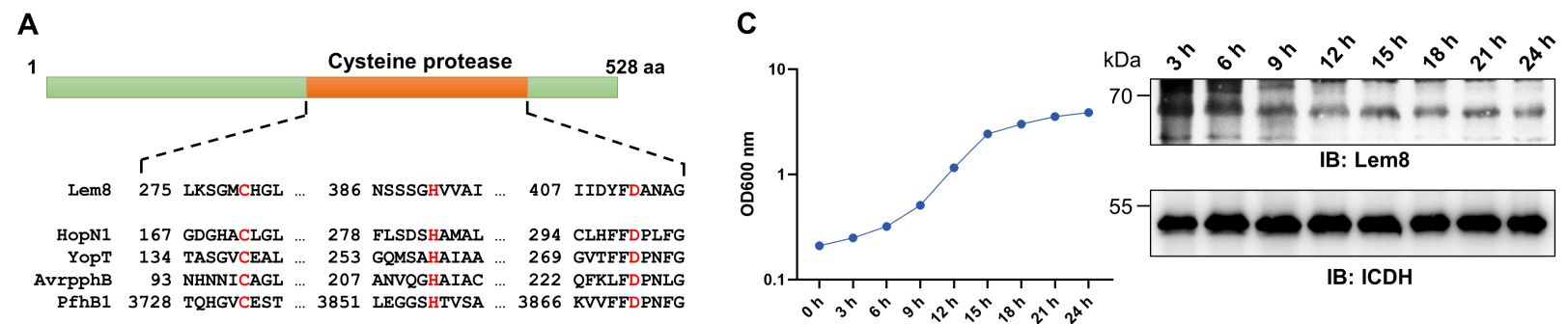

\section{B}
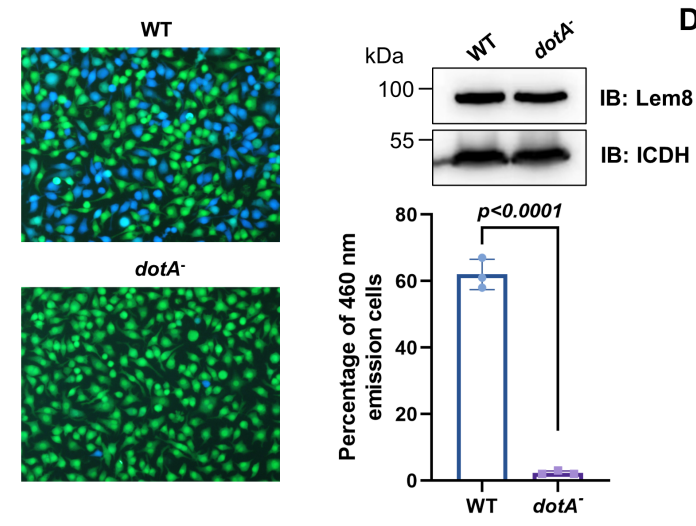

D

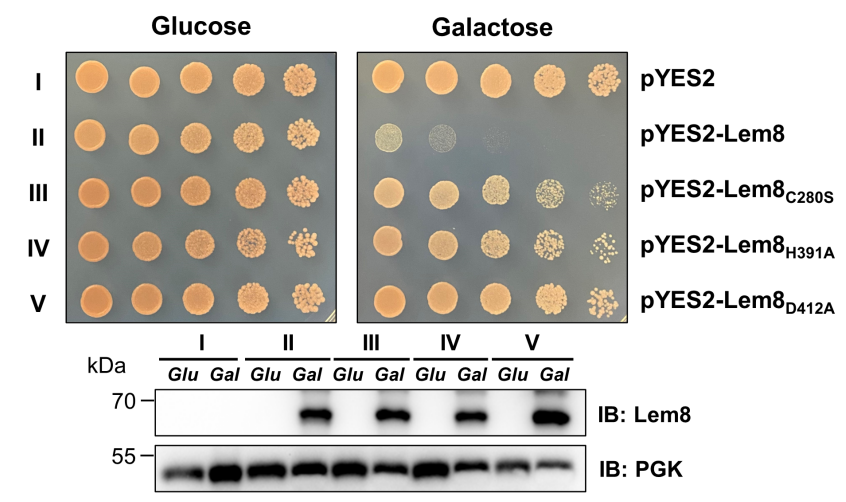


A

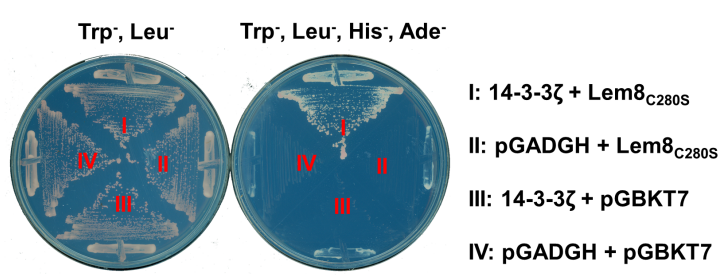

C

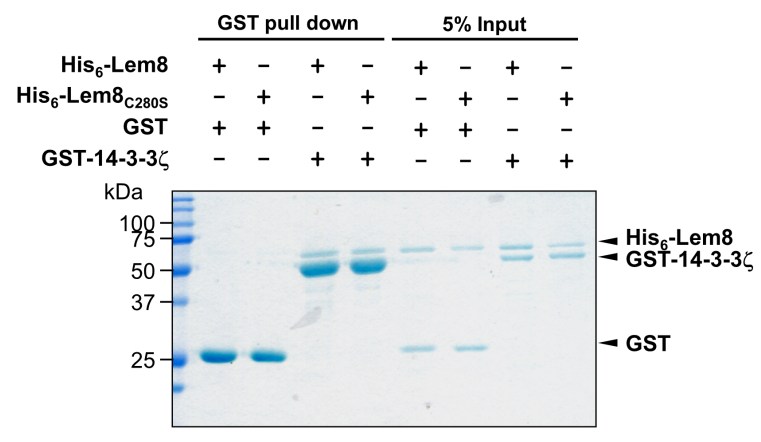

B
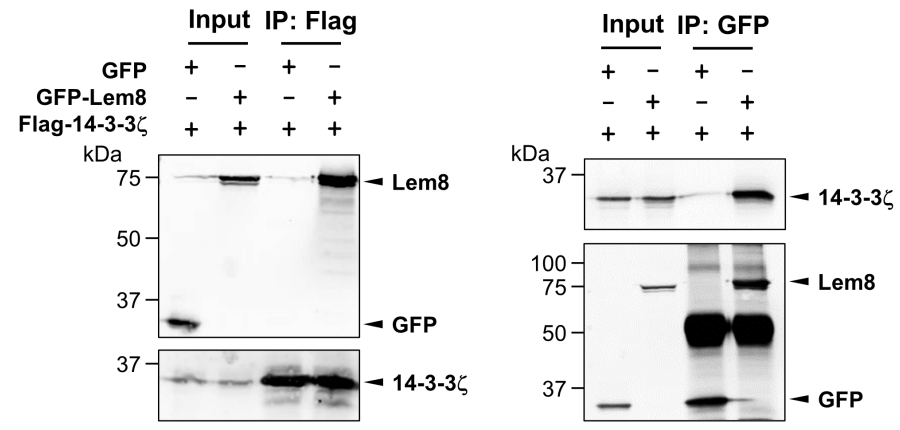

D

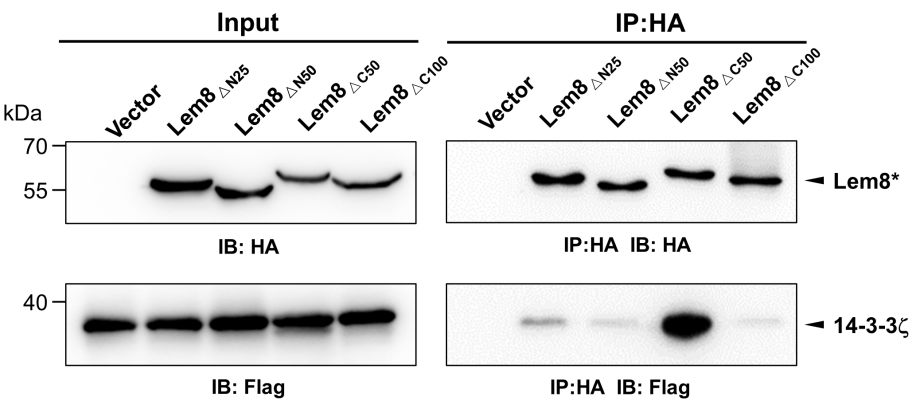


A

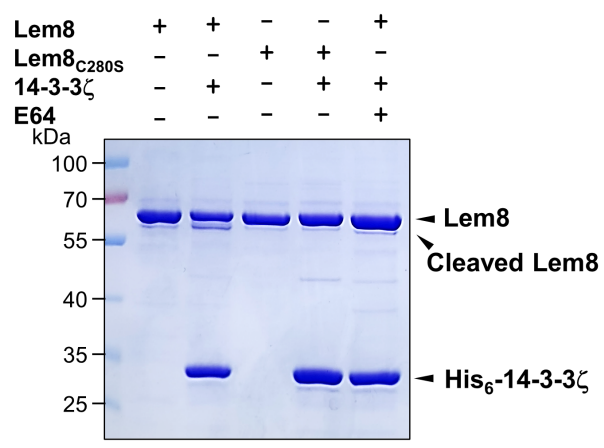

C

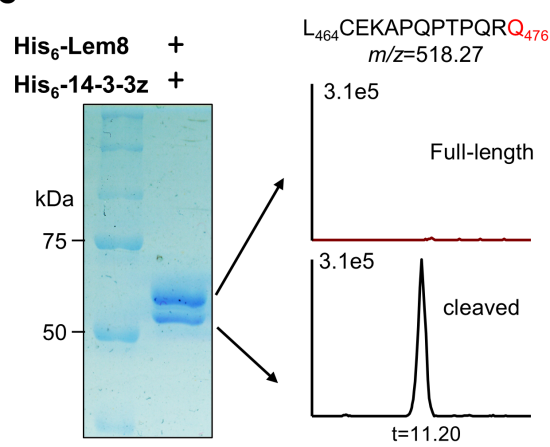

B

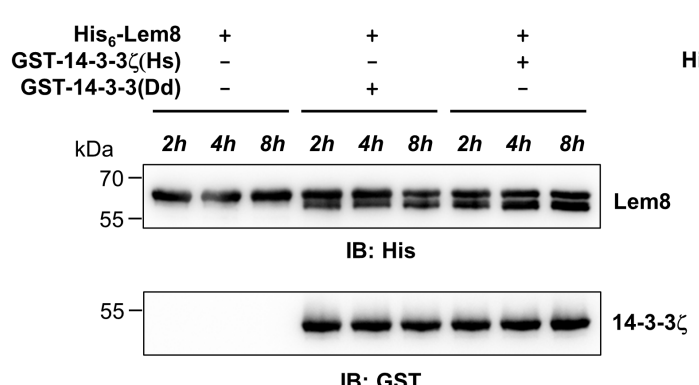

IB: GST
D

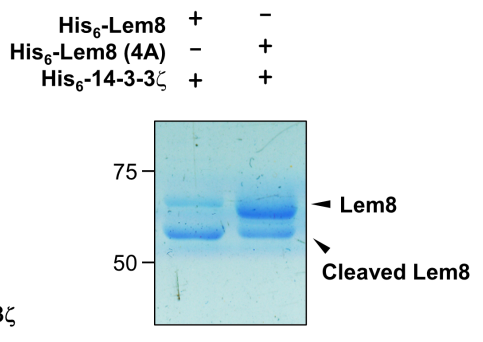

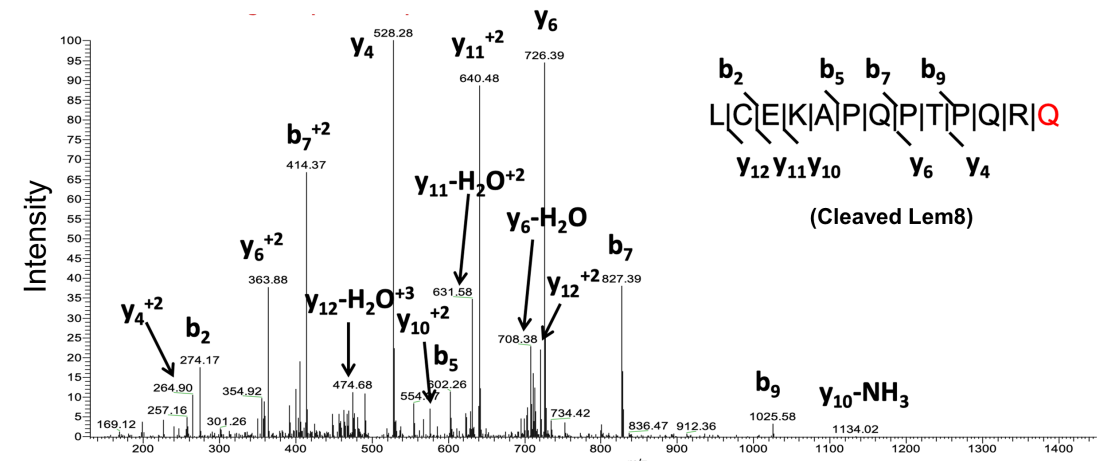


A

$\begin{array}{lrl}\text { Lem8 } & 470 & \text { QPTPQRQRAQSLSA } \\ & & \\ \text { Phldb2 } & 1106 & \text { VKIRERQRAQARPL } \\ \text { Rasgrp2 } & 544 & \text { LSVECRRRAQSVSL } \\ \text { Pak6 } & 103 & \text { RSPTSRRRAQSLGL } \\ \text { Exoc8 } & 40 & \text { DLQEHRQRIQALAE } \\ \text { Ankrd13b } & 554 & \text { PPTPQRQPAPPASV } \\ \text { Chkb } & 30 & \text { DTTPKRRASSLSR } \\ \text { Ppp6r1 } & 850 & \text { LGLPQSQSAQALTP } \\ \text { Kiaa1033 } & 387 & \text { RDTFLQQKAQSLTK } \\ \text { Gnal } & 70 & \text { KPKEKRQRTEQLSA } \\ \text { Gpr61 } & 248 & \text { WMETPRQRSESLSS }\end{array}$

C

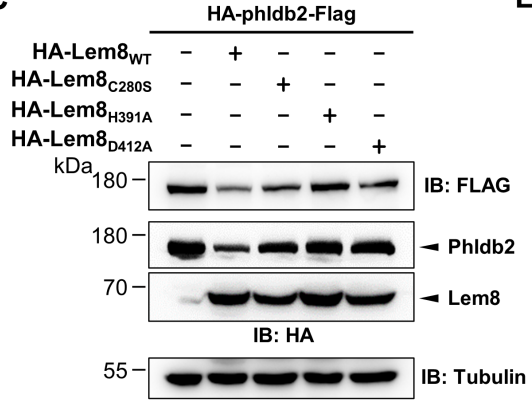

B

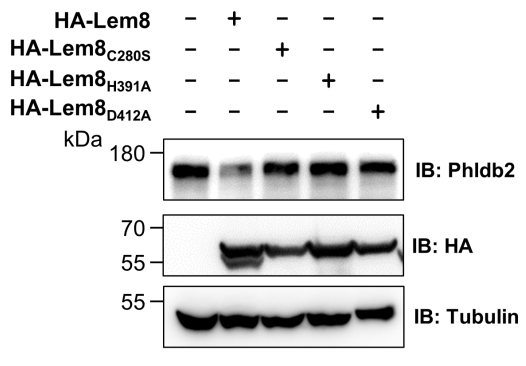

E

\section{D}

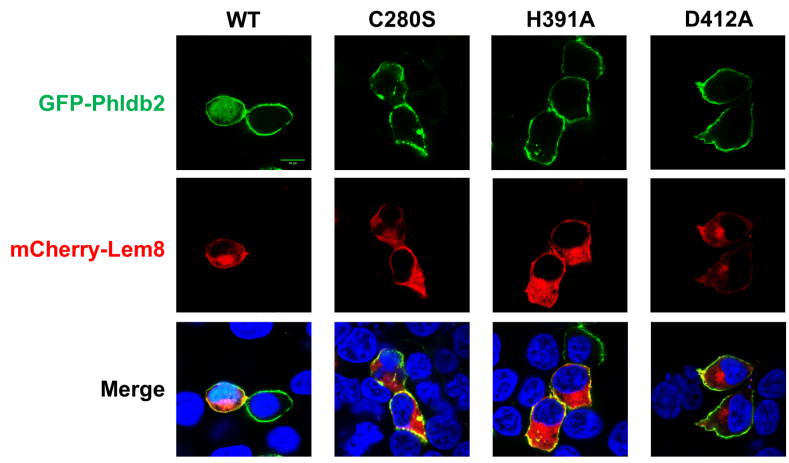

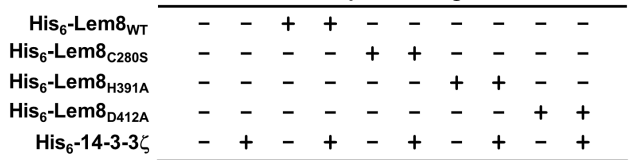

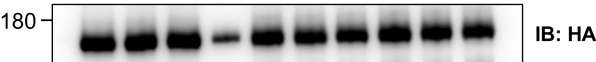

180- IB: Flag

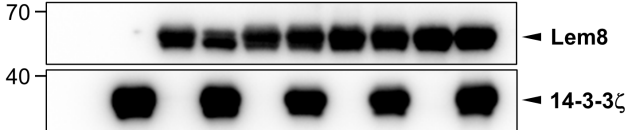

IB: His

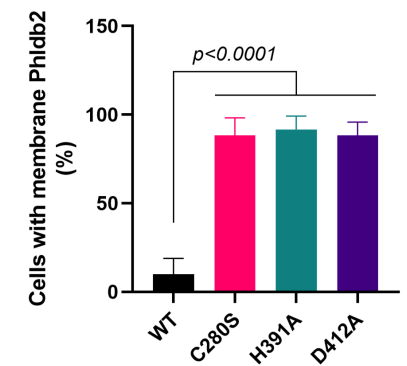


A

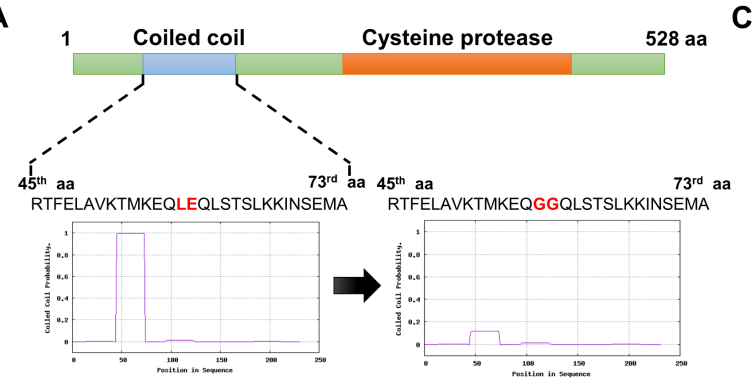

B

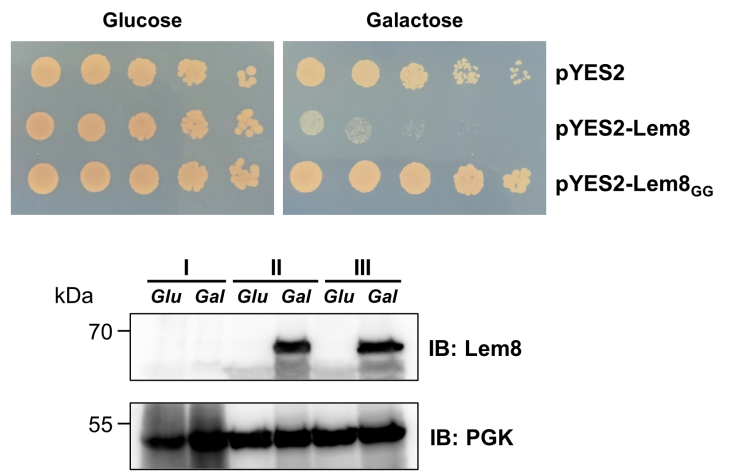

C

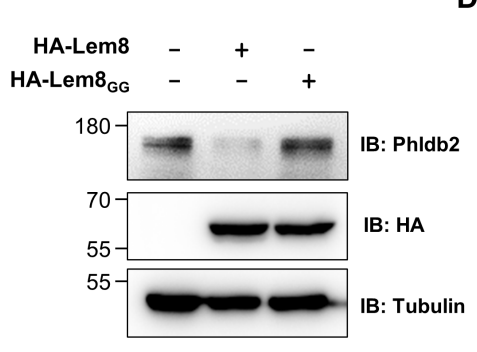

E

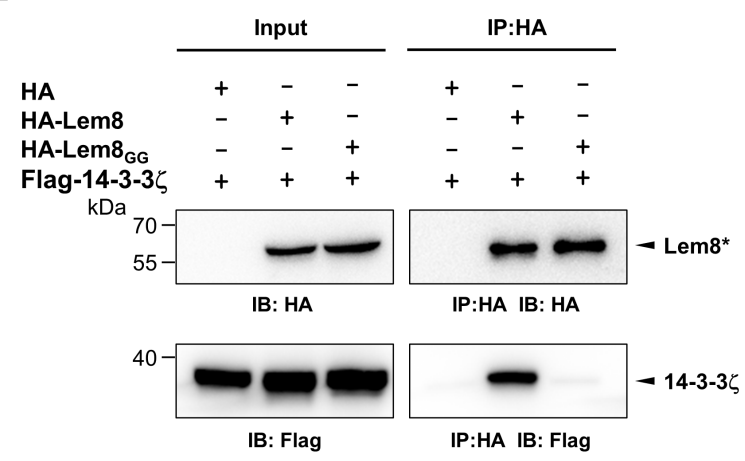


A
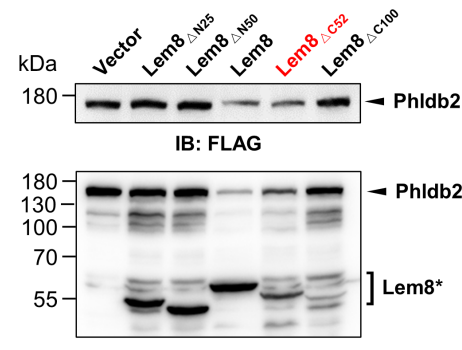

IB: HA

55

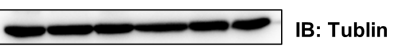

C

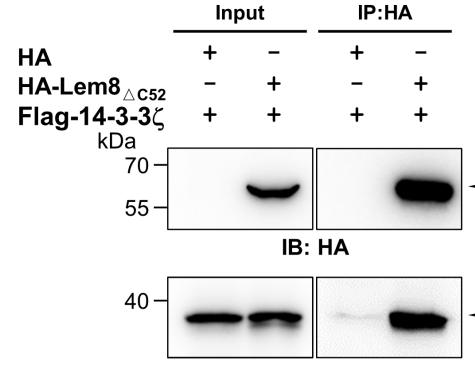

IB: Flag
B

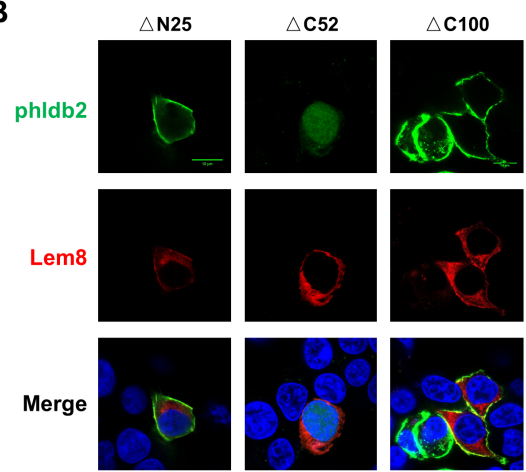

Flag

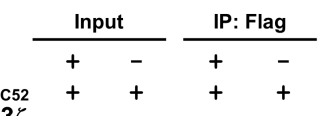

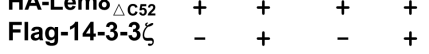
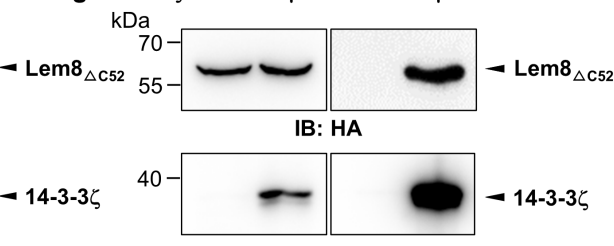

IB: Flag

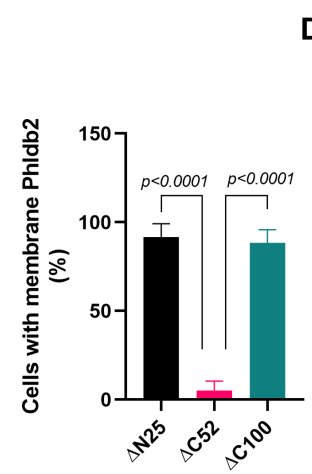

D

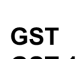

$\begin{array}{lllll}\mathrm{His}_{6} \text {-Lem8 } & - & + & - & + \\ + & + & + & +\end{array}$

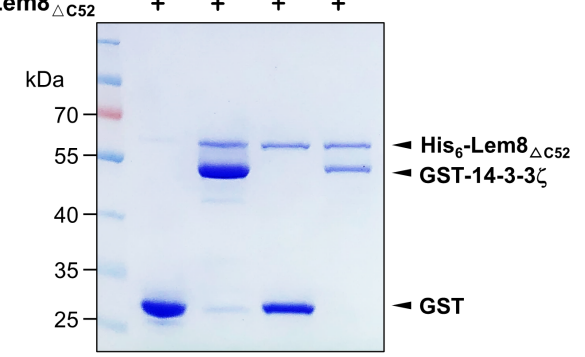

E

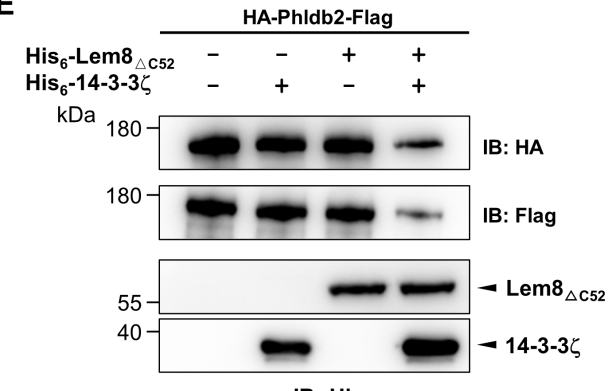

IB: His 
A

B
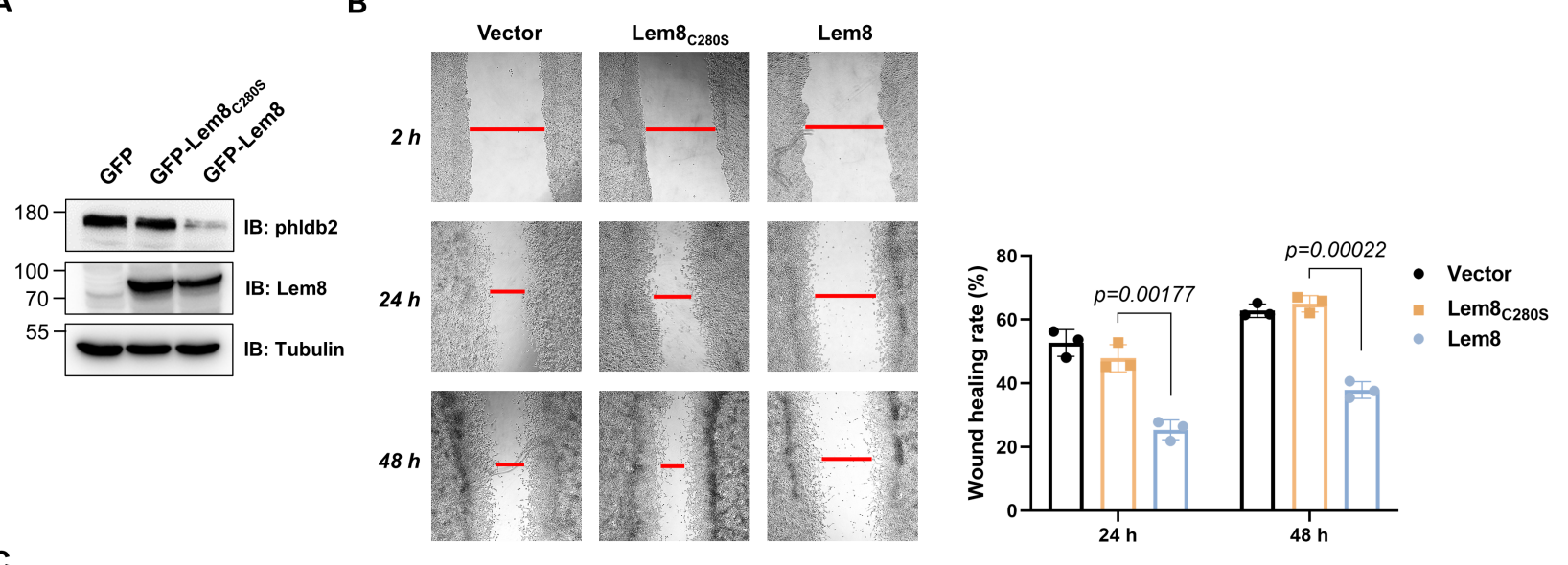

C
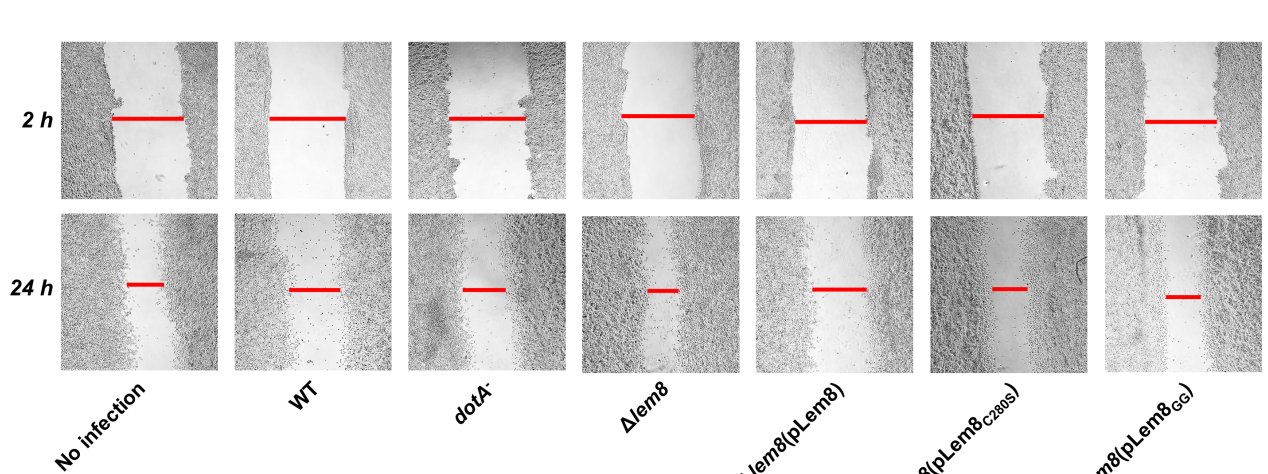

and $0^{2}$

D
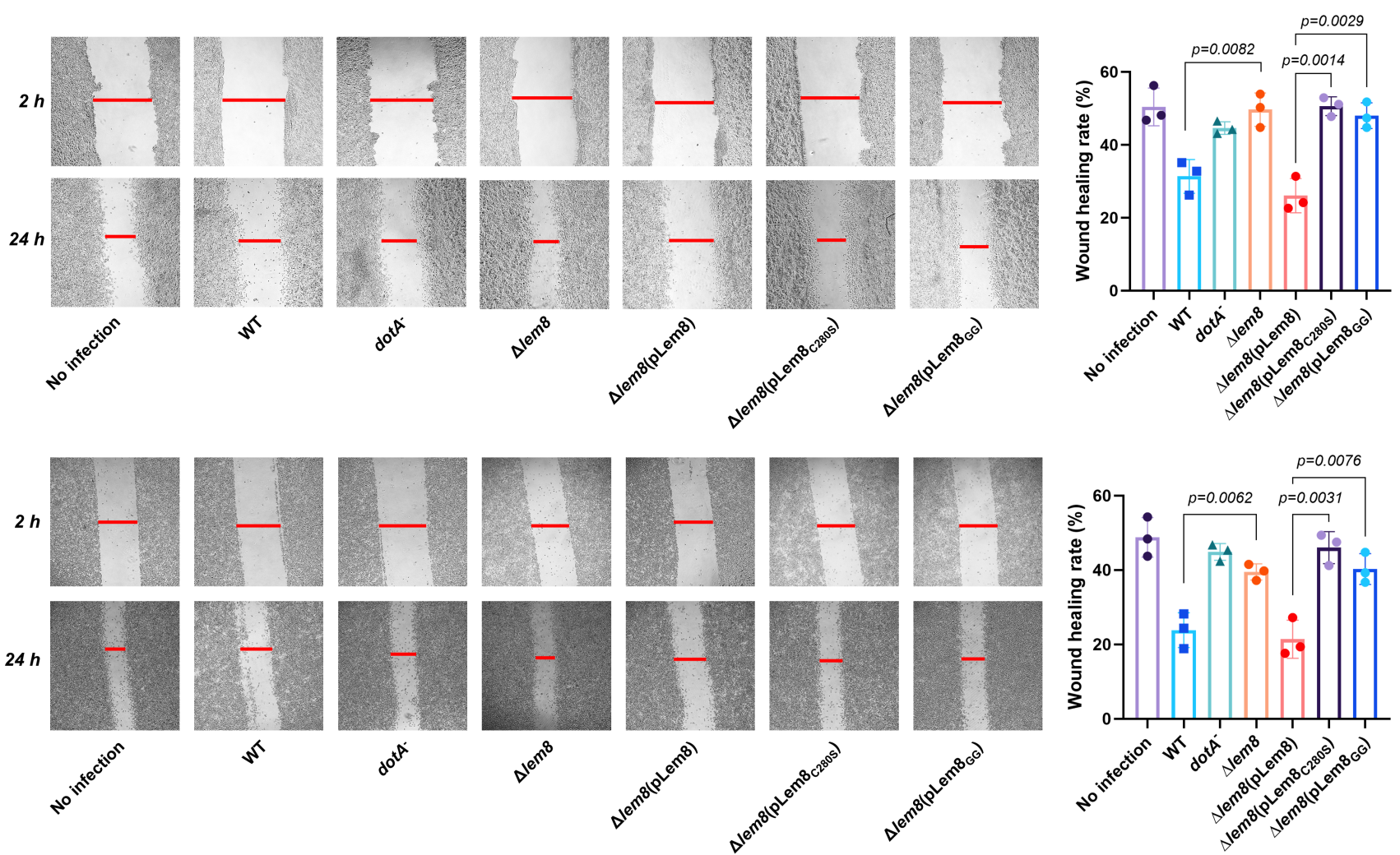
247 a AYRHQEKCRELGGR I VLHCSQ - . . . . . . . . . AMLPGMGLKSGMCHGLARHWANDV I KKD 295 aa 60 aa GDKG - - CASS - SGVSLEDDSHTQVSLSDFS - . . . - . VASRDVNHNN ICAGLSTEWLVMSSDGD 113 aa 99 aa VPAVRESVANYGGN I NFKFAQ - TKGAFL - HK - . . - . I I KHSDTASGVCEALCAHWIRSH - AQ 152 aa 3693 aa I DAVRSSVEEFGGEVSFKYAQ - SKGEVY - NE - . . . . I IKHVDTQHGVCESTCAHWI ANKVSSQ 3748 aa

296 aa RFMGF - . - RGNQEVS IQPTK - . . . . . . ATDKI LQA I PSFNDFVRLNPKIYETQQSQKEH 344 aa 188 aa SDEAFFHKLEDYQGDALLP - R VMGFQH I EQQAYSNKLQN - - AAP - - - MLLDTLPKLGMTL - - - GK 243 aa 114 aa AESRMDHLDYNGEGQSRGSER - - - HQVYNDALRAALSNDDEAPFFTASTAVIEDAGFS - - - - - 168 aa 153 aa GQSLFDQLYVGGRKGKFQ I DTLYS I KQLQ I DGCKA - - - - DVDQDEVTLDWFKKNG I SERM IERH 212 aa 3749 aa GEDFWNTMYEGGKKGHLKQEA I DS I KKLQTEF I QSGS - - - A TQQFKL TDNWLQEQGVVPKEKKVG 3810 aa

140 150

160 170 180 190

Lem8

HopN1 Avrpph3

YopT 345 aa I FLEYEDTVGSEPEKQFEEFTDR IM - SELDKYGKSATFVSYANSSSGHVVA I HKRTKPTPQGF I I D 409 aa 244 aa GLGRAQHAHYAVALENLDRDLKAVLQP - . - - GKDQML - L - F - LSDSHAMALH - . - - QDSQGCLH 296 aa 169 aa - - LRRE - PKT VHASGGSAQLGQTVA - HDVAQSGRKHLLSLRFANVQGHA I A - C - - - - SCEGSQFK 224 aa 213 aa CLLRPVDVTGT TESEGLDQLLNA I LDTHG I GYGYKK - I HLSG - QMSAHA I AAY - - - - VNEKSGVT 271 aa 3811 aa DLSRRDEVAGTVSKSD I SALTKA I LDTGSDTAGAKK - I S I NL - EGGSHTVSAL - - - - I - QGEKVV 3868 aa

200 210 220 230 240

Lem8 HopN1 Avrpph3 410 aa YFDANAGWMQFKDDKSFQEFLTYYLNDRH - . . . . - AKEKLKS I AFETLCY 453 aa 297 aa FFDPLFGVVQADSFSNMSHFLADVFKRDVGTHWRG - TEQRLQLSEMVP - - R 344 aa 225 aa LFDPNLGEFQSSRSAAPQ - L . . . . . . I KGL I DHYNSLNYDVACV 261 aa 272 aa FFDPNFGEFHFSDKEKFR KWF TNSFWGNSMYHYPLGVGQRFRVLTFDSKEV 322 aa 
A

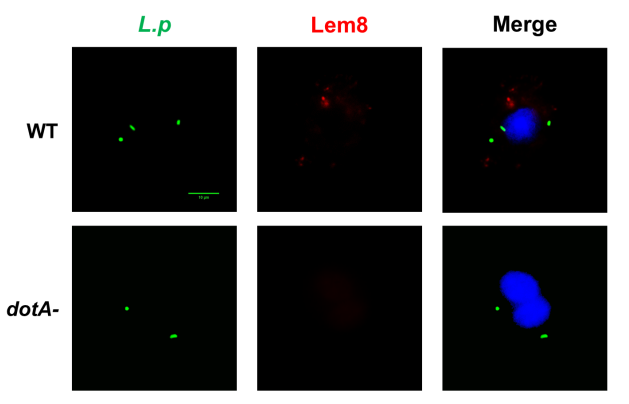

C

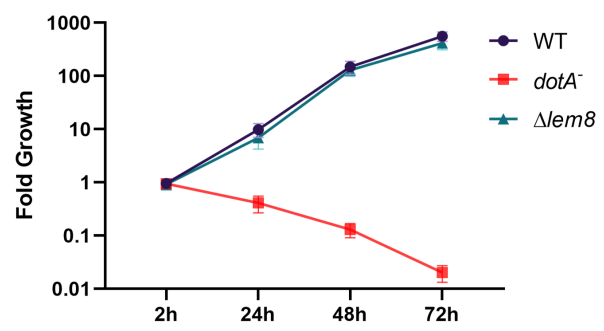

B

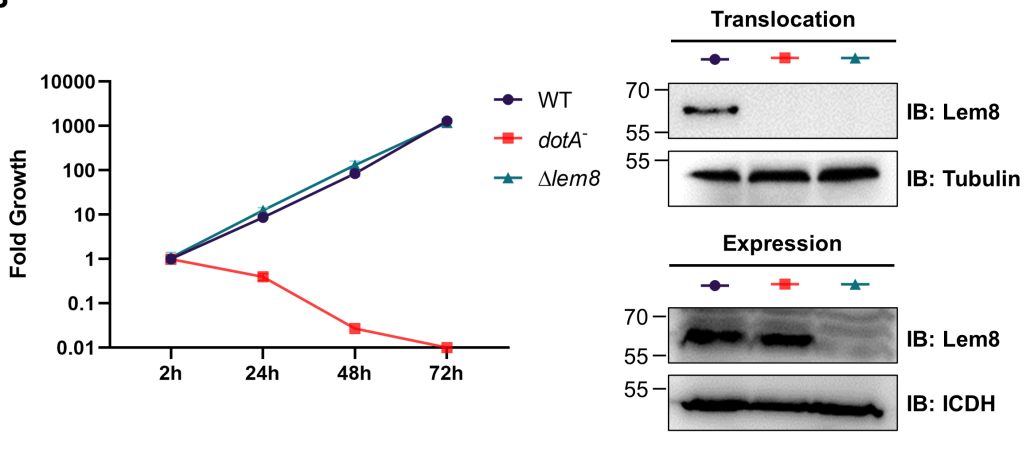




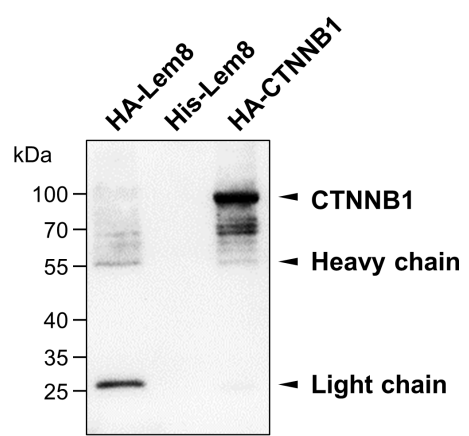

IB: pan phospho-serine/threonine antibody
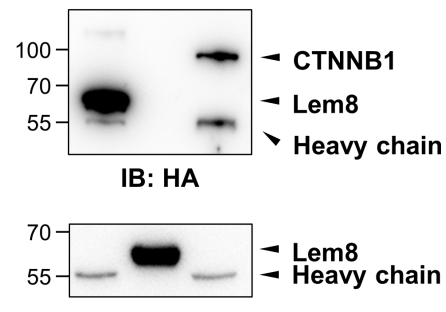

IB: His 
A

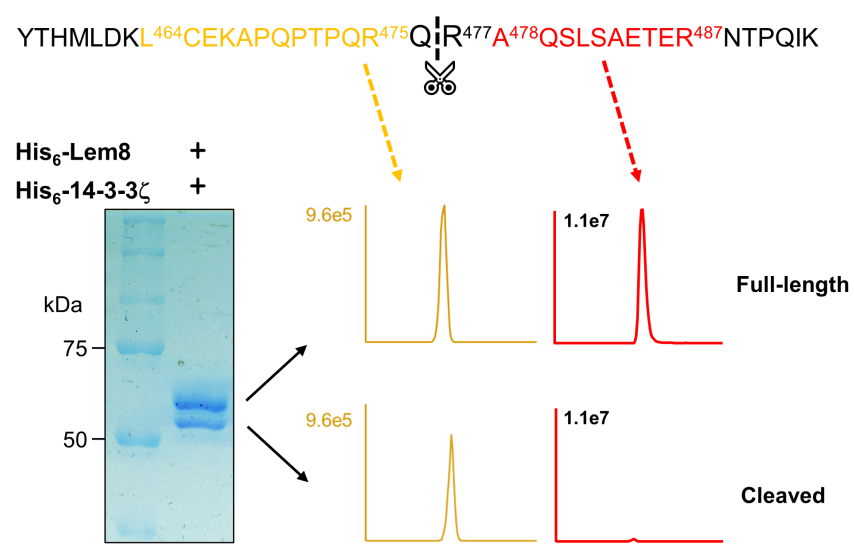

B

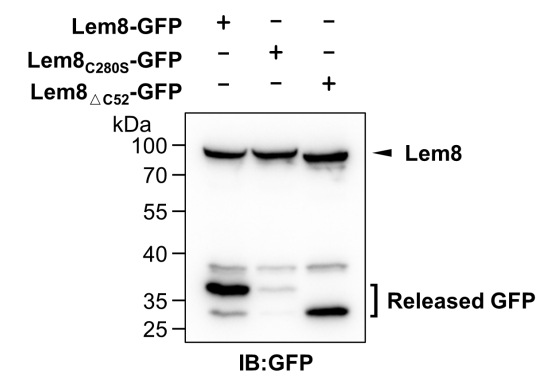

C

HAK EKLKS ${ }^{445}$ |AFETLCYPSSYTHMLDKLCEK $K^{467}$ A68 PQPTPAAAAAQSLSAETER $^{487}$ NTPQIK

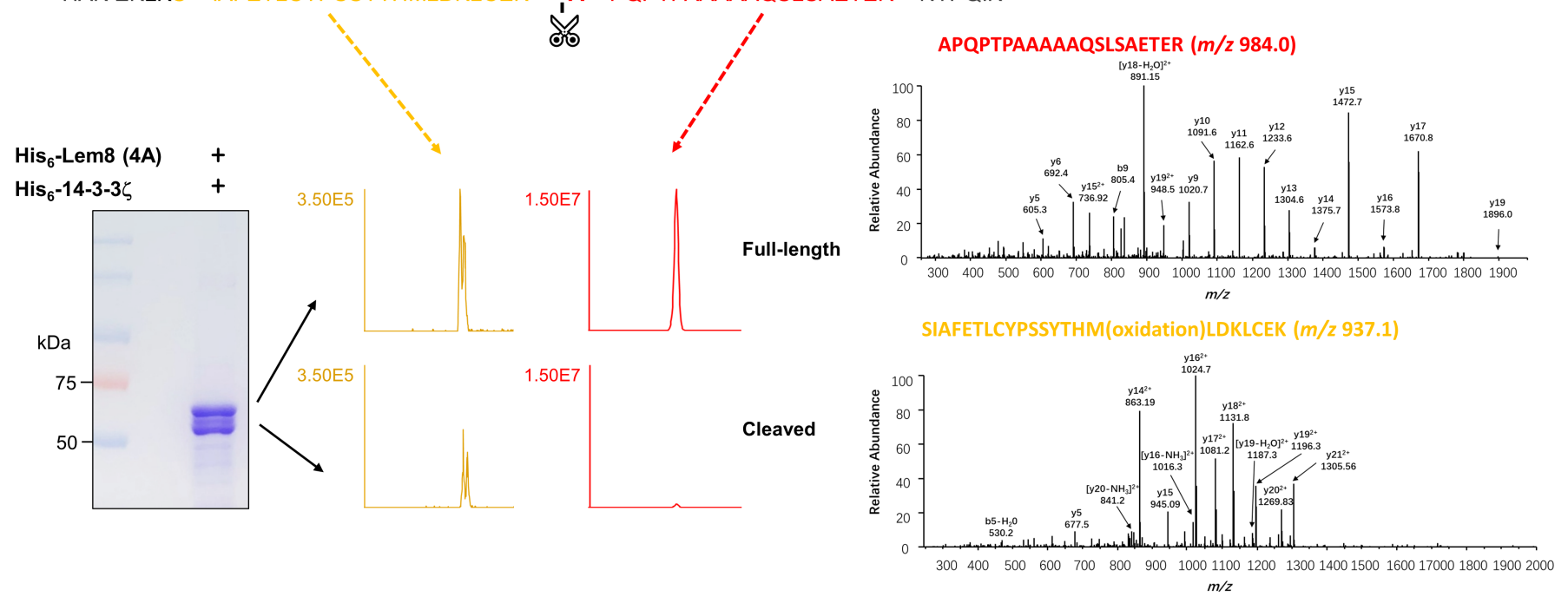


A

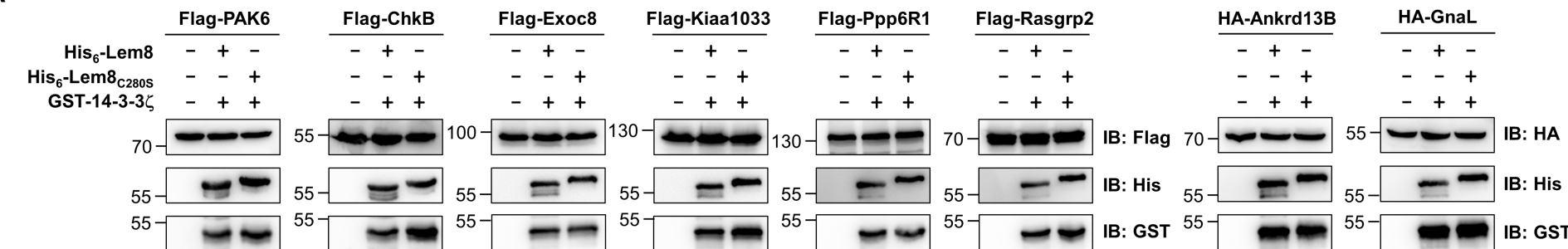

B

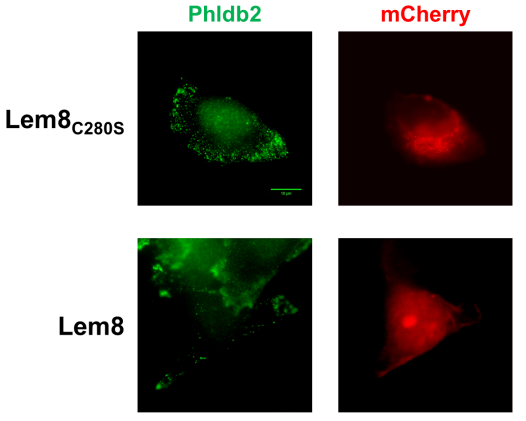

C

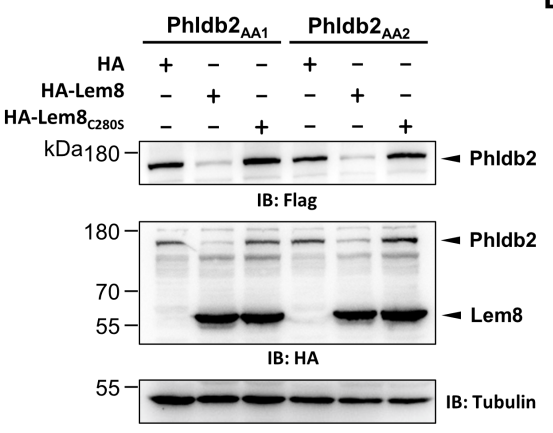

Hochest
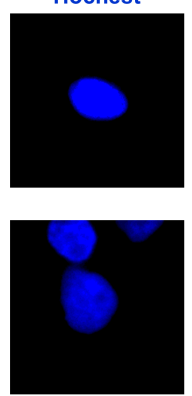

D

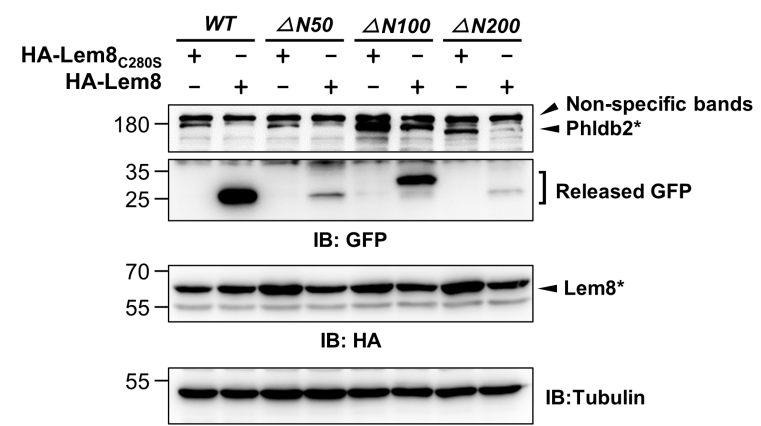

E
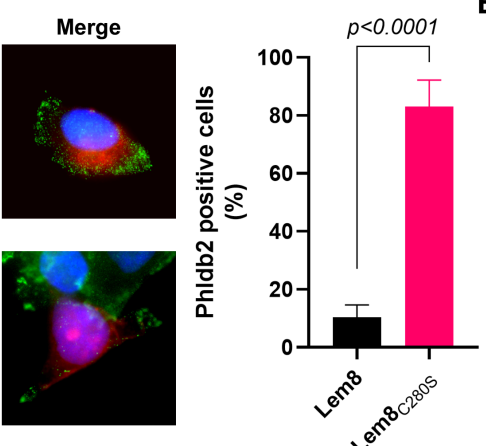

I: No infection II: WT

III: $\operatorname{dot} A^{-}$

IV: $\Delta / e m 8$

V: $\Delta / e m 8($ Lem8)

VI: $\Delta / e m 8$ (Lem8 $\left._{\text {c280S }}\right)$
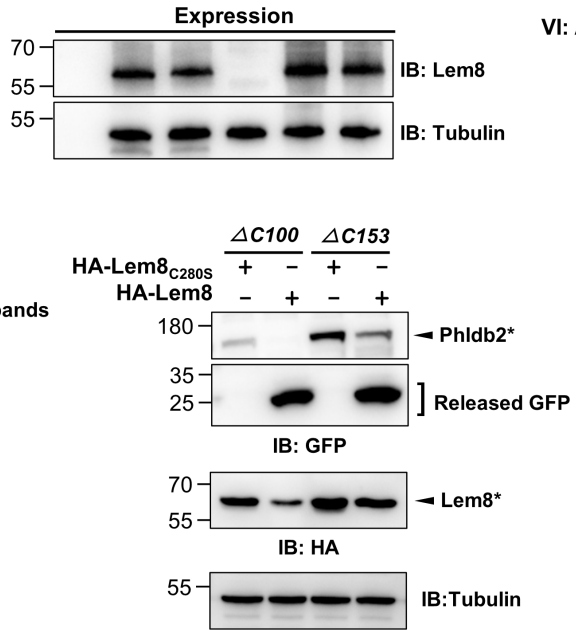
A

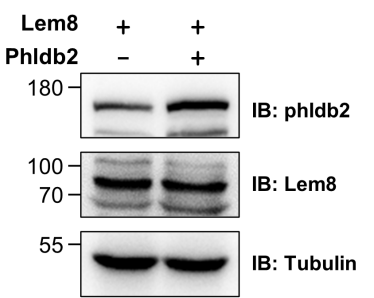

B

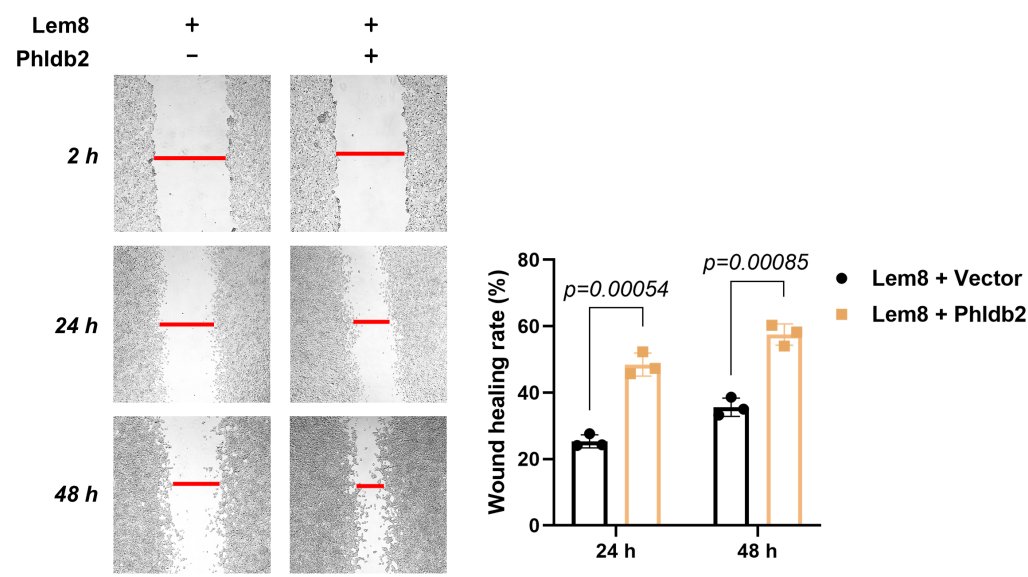

